Max-Planck-Institut für demografische Forschung

Max Planck Institute for Demographic Research

Konrad-Zuse-Strasse 1 · D-18057 Rostock · GERMANY

Tel +49 (0) 3812081 - 0; Fax +49 (0) 3812081 - 202;

http://www.demogr.mpg.de

MPIDR WORKING PAPER WP 2016-006

AUGUST 2016

\title{
Recent Trends in US Working Life \\ Expectancy at Age 50 by Gender, Education, and Race/Ethnicity and the Impact of the Great Recession
}

Christian Dudel (dudel@demogr.mpg.de)
Mikko Myrskylä (sekmyrskyla@demogr.mpg.de)

(C) Copyright is held by the authors.

Working papers of the Max Planck Institute for Demographic Research receive only limited review. Views or opinions expressed in working papers are attributable to the authors and do not necessarily reflect those of the Institute. 


\title{
Recent Trends in US Working Life Expectancy at Age 50 by Gender, Education, and Race/Ethnicity and the Impact of the Great Recession
}

\author{
Christian Dudel
}

Max Planck Institute for Demographic Research

\author{
Mikko Myrskylä ${ }^{\dagger}$
}

Max Planck Institute for Demographic Research

Department of Social Policy, London School of Economics and Political Science

Population Research Unit, University of Helsinki

\begin{abstract}
A key concern about population aging is the decline in the size of the economically active population. Working longer is a potential remedy. However, little is known about the length of working lives. We use the US Health and Retirement Study for 1992-2011 and multistate life tables to analyze working life expectancy at age 50 by gender, race/ethnicity, and education. Despite declines of 1-2 years following the Great Recession, in 2008-2011 American men aged 50 still spent 13 years, or two-fifths of their remaining life, working; while American women of the same age spent 11 years, or one-third of their remaining life, in employment. At age 50, the working life expectancy of college-educated individuals is twice as long as that of individuals with no high school education, and the working life expectancy of whites is one-third longer than that of blacks or Hispanics. These differentials are driven by labor force attachment, not mortality. Although educational differences have been stable over the past 20 years, racial differences started changing after the onset of the Great Recession. Our results show that while Americans generally work longer than people in other countries, there is considerable sub-population heterogeneity. We also find that the time trends are fluctuating, which may prove troublesome as the population ages. Policies targeting the weakest performing groups may be needed to increase the total population trends.
\end{abstract}

${ }^{*}$ Corresponding author; address: Max Planck Institute for Demographic Research, Konrad-ZuseStr. 1, 18057 Rostock, Germany; email: dudel@demogr.mpg.de; phone: +49 381 2081221; fax: +49 3812081521

†Email: myrskyla@demogr.mpg.de 


\section{Introduction}

Population aging is one of the major global changes of the 21st century. In the coming decades, the number of people aged 65 or older will grow substantially in the vast majority of countries (United Nations, 2015). The growth in the older population is occurring rapidly in the developing world, but the starting levels in these countries are low. Meanwhile, many developed countries are already gray. In Europe (EU-28), the share of the population aged 65 or older was $19 \%$ in 2015, and is projected to increase to $28 \%$ by 2060 (Eurostat, 2015). Although the US is generally not considered to be among the graying nations because of its relatively high fertility and positive net migration, the US Census Bureau predicts an increase in the proportion of the population aged 65 and older in the coming decades, from $15 \%$ in 2014 to $24 \%$ in 2060 (Colby and Ortman, 2015).

The main concerns that arise in discussions about population aging in the US and elsewhere are related to the long-term sustainability of social security systems. Without changes in labor force participation patterns, population aging will result in a decrease in the proportion of the population who are economically active. A potential remedy to the challenges associated with population aging is to extend people's working lives. Accordingly, policies are being implemented that aim to increase labor force participation, particularly among the older population. In many European countries the retirement age has been increased, financial incentives to stay in the work force longer have been introduced, and regulations regarding early retirement have been reformed (OECD, 2013, 2015b). In the US, the Social Security retirement age has been increased from age 65 to 66 (Behagel and Blau, 2012).

Although this issue is of critical importance for the long-term sustainability of aging countries, little is known about precisely how long people work. This lack of knowledge stems at least in part from measurement problems. Indicators reflecting retirement age are most often used as proxies for the length of working life. However, relatively few individuals exit or retire from the labor force upon reaching the normal age of eligibility to receive a full old-age pension, as individual factors such as health, and structural factors such as the availability of a disability pension, may create incentives for workers to retire earlier or later than the statutory retirement age (Leinonen et al., 2016a). Moreover, individuals may return to employment after a period of retirement (Hayward and Grady, 1990; Hayward et al., 1994; Cahill et al., 2015). In short, in many cases retirement is not a single, clearly defined event; but a process (Marshall et al., 2001).

An alternative way to measure the length of working life is to construct working life tables from which it is possible to calculate the average number of years people spend employed. This approach, which can be implemented by modeling the transitions between labor force states and mortality with Markov models, has been used in a number of studies, including Hoem (1977), Hayward and Grady (1990), and Millimet et al. (2003). Among the advantages of using the Markov chain approach are that multiple entries and exits to and from employment, as well as mortality, are accounted for; and that the standard demographic decomposition tools that allow for the analysis of the determinants of changes and differences are immediately available. In addition, focusing on working life expectancy makes it possible to circumvent the many pitfalls associated with attempting to define retirement when analyzing "age 
at retirement". We have therefore chosen to follow this methodological approach, using data from the Health and Retirement Study (HRS) to analyze working life expectancy at age 50 in the US population and its sub-populations. While our focus is on working life expectancy, we also report estimates for the proportion of remaining life expectancy at age 50 that is spent working. This allows us to measure to what extent people spend their additional years of life working or in an economically inactive state. The analysis fills several gaps in the literature on the length of working life in the US.

First, there is little knowledge on recent trends in working life expectancy in the US. Studies conducted in other countries have found that working life expectancy has been changing. For example, Nurminen et al. (2005) and Leinonen et al. (2016b) reported gradual increases in the average length of working life at age 50. However, most US-related studies have focused on a single period. An exception is Skoog and Ciecka (2010), who analyzed the Current Population Survey and documented that between 1970 and 2003, there was little change in working life expectancy measured at age 20 for men, but some increases for women. Analyzing recent trends in working life expectancy at older ages might yield valuable insights. It is especially interesting to study the effects on older workers of the 2007-2009 recession, which was the most severe economic downturn since World War II, and is aptly called the Great Recession (Goodman and Mance, 2011). Looking at the total population, there is general consensus that men were more affected than women, whites more than blacks, and the less educated more than the better educated (Engemann and Wall, 2009). However, the results regarding the impact of the Great Recession on older age groups are less clear-cut. While (Engemann and Wall, 2009) reported that employment increased when measured as the number of workers aged 55 and older, both Farber (2011) and Cahill et al. (2015) found sharp increases in the unemployment rates of older workers. Moreover, Coile and Levine (2011) found that during the recession unemployed workers had a higher probability of retiring than employed workers. On the other hand, Hurd and Rohwedder (2010) presented findings that suggest that the recession may have led to the postponement of retirement due to the negative impact of the downturn on wealth, and especially on home equity. The net impact of the recession on working life expectancy remains unclear, and it is hard to predict whether the crisis has led to an increase or a decrease in working life expectancy.

Second, there is little research on racial/ethnic variations in working life expectancy at older ages, despite the marked racial/ethnic differences in labor force participation (Flippen and Tienda, 2000), life expectancy (Lariscy et al., 2015), and disability and active life expectancy (Hayward and Heron, 1999). The existing studies analyzed differences between whites and non-whites, while minority groups are heterogeneous. Using period working life tables, Smith (1986) found that the differences between whites and non-whites are relatively small among women, and are larger among men. Applying a similar methodology to analyzing 1990-2000 Current Population Survey data, Millimet et al. (2003) came to the same conclusions, noting that the differences between white and non-white males diminish with age. Hayward and Grady (1990) used cohort data to compare white and black males, and reported only a small gap in working life expectancy.

Third, whereas the number of studies on racial/ethnic differences in working life expectancy is small, there is a much larger body of literature on educational 
differences in working life expectancy in the US. All of these studies have found differentials that suggest that the better educated work longer (Smith, 1986; Hayward and Grady, 1990; Millimet et al., 2003). However, no study has analyzed working life expectancy by education within racial/ethnic groups. The results of prior research suggest that the educational gradient in mortality within working ages (Jemal et al., 2008) and older ages (Meara et al., 2008) is strongly dependent on the racial/ethnic group analyzed, with African American men having the steepest mortality gradient, and Hispanic men and women having a relatively flat mortality gradient. The association between education and the probability of being employed has also been shown to vary greatly by race/ethnicity, such that the employment rate gradient by education is steepest among blacks and flattest among Hispanics (Bureau of Labor Statistics, 2015). This would suggest that the educational differences in working life expectancy differ markedly by racial/ethnic or ethnic group.

We use 20 years of data of the HRS and calculate period working life tables for five-year intervals to analyze recent developments in working life expectancy (WLE) at age 50 in the US, focusing on differences by gender, education, and race/ethnicity. In addition to generating findings on WLE by gender and education, we provide detailed results for whites, blacks, and Hispanics; as well as for the interaction of gender, race/ethnicity, and education. We also analyze how the Great Recession affected WLE, and how its impact varied across different groups. Moreover, we present a methodology that allows us to match our period working life tables with external life tables.

\section{Data and methods}

\subsection{Data}

The Health and Retirement Study (HRS) is a panel study that has been running since 1992, and that focuses on Americans over the age of 50 (Juster and Suzman, 1995). The survey is conducted by the Survey Research Center of the Institute for Social Research of the University of Michigan, and is supported by the National Institute on Aging and the Social Security Administration.

The interviews are conducted every two years. In addition to questions on the labor force status at the time of the interview, several retrospective questions cover the time between two consecutive interviews. The year of death is obtained from either interviews with relatives or from the National Death Index.

We measure employment based on self-reported labor force status. We distinguish between three different states: "employed", "retired", and "out of the labor force (but not retired) or unemployed". Respondents who report that they are working or are on leave (e.g., sick leave) are classified as employed. Respondents who report either that they are retired or that they are out of the labor force or unemployed and are over age 65 are classified as retired. Finally, the last category of unemployed or out of the labor force is comprised of non-retired individuals who report that they are unemployed, disabled, a homemaker, or doing something other than working. While this last group is heterogeneous, this diversity is acceptable as our focus is on working life expectancy.

We construct a working history for each respondent, focusing on annual transitions. 
To achieve this, we exploit the fact that labor force status is recorded to the nearest month. We use the status in the month of December to define the individual's labor force status. For example, if a respondent was employed in December 1996 and retired in December 1997, we use the status employed for 1996 and the status retired for 1997. A detailed description of the constructed working histories is given in Dudel (2016).

Race/ethnicity is assigned based on two questions. All of respondents who identify as Hispanic are classified accordingly. Respondents who do not identify as Hispanic are assigned a race/ethnicity based on another set of questions in which they are asked whether they primarily identify as white, black, American Indian/Alaskan Native, Asian/Pacific Islander, or something else. The latter three groups are subsumed in the category "other". As the number of respondents in this category is rather small, no analysis was conducted for this group. Educational status is broken down into the following categories: less than a high school degree, a high school diploma or GED, and a college or university degree.

\subsection{Modeling approach}

We use Markov models to model the transitions between labor force states (Hoem, 1977; Skoog and Ciecka, 2010). The starting point is transition probabilities $p(i \mid x, j)$, which give the probability that an individual aged $x$ and in labor state status $j$ will be in status $i$ at age $x+1$. Our state space consists of the transient labor force states "employed", "retired", and "out of the labor force or unemployed"; and of the absorbing state "dead". The starting age is 50 and the maximum age is age 99, whereby those individuals who are still alive die with a probability one. We assume for individuals ages 65 and older that they are either employed or retired, and that the state "out of the labor force or unemployed" is no longer relevant. Figure 1 depicts the state space ignoring age.

Transition probabilities are used to construct working life tables. Working life tables are calculated for the years 1993-1997, 1998-2002, 2003-2007, and 20082011. For each period the results are derived differentiated by gender; by gender and race/ethnicity; by gender and education; and by gender, race/ethnicity, and education jointly. We use weighting to obtain working life expectancies without conditioning on the initial state. More formally, if $\operatorname{WLE}(x, j)$ denotes the working life expectancy for individuals aged $x$ and in state $j$, the working life expectancy by age, $\operatorname{WLE}(x)$, can be calculated as $\operatorname{WLE}(x)=\sum_{j} \operatorname{WLE}(x, j) w_{j}(x)$, where $w_{j}(x)$ denotes some weight for age $x$ and state $j$. We use weights for age 50 only, and otherwise report the results by age and state otherwise. Weights $w_{j}(50)$ were calculated from the empirical distribution of labor force states at ages $45-54$ in all years by gender; gender and race/ethnicity; gender and education; or gender, race/ethnicity, and education. We combined the ages 45-54 and all years to increase the sample size for the initial distributions. The weights are time-constant so that differences between results by period are not due to differences in the distribution of states. 


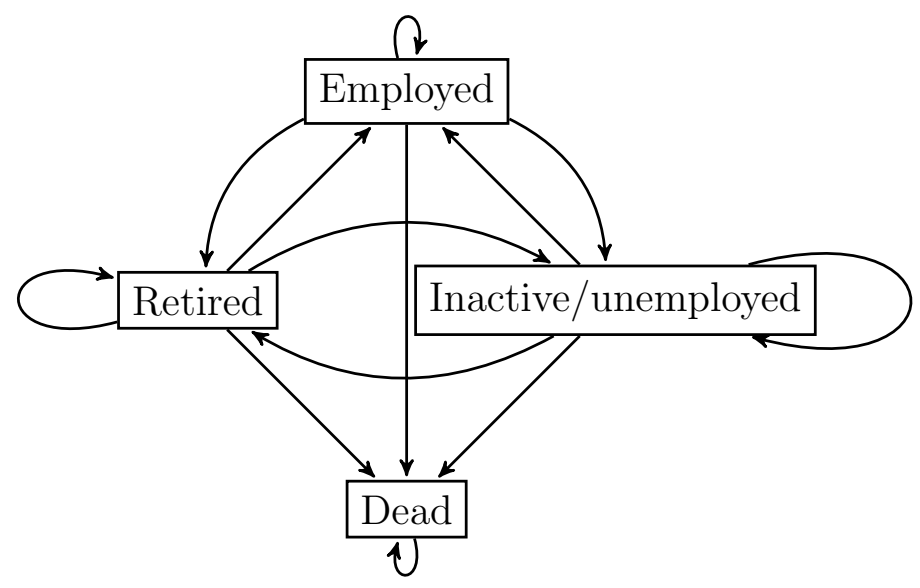

(a) State space for ages 50 to 64

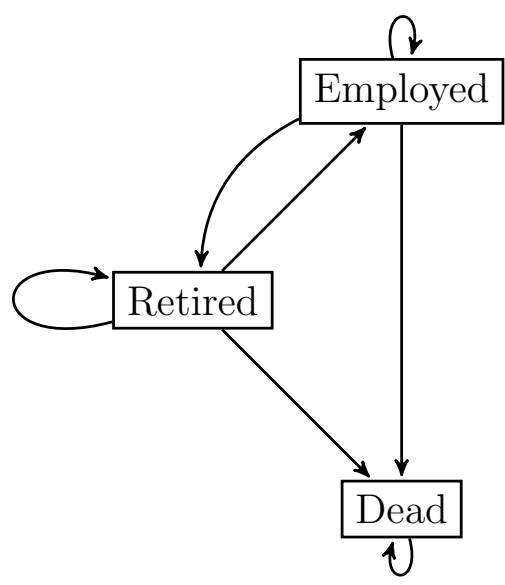

(b) State space for ages $65+$

Figure 1: State space of the Markov model for ages 50 to 64 (upper figure) and state space of the Markov model for ages $65+$ (lower figure).

\subsection{Estimation of transition probabilities}

To estimate transition probabilities, we use multinomial logistic regression (Greene, 2012). Each transition is treated as an observation with state at time $t+1$ as the dependent variable, and state at time $t$ as one of the explanatory variables. Age is modeled using a smoothing spline (Yee and Wild, 1996). In addition, dummies were included to capture discontinuities in the age schedules (Behagel and Blau, 2012): two dummies were used to capture peaks in retirement at ages 65 and 66, respectively; another dummy covers ages 62 to 64 , and a fourth dummy covers ages of 67 and above. Education was used as an explanatory variable as well as interactions of education and period. Estimates by gender and by gender and race/ethnicity are achieved by stratifying the sample into subsamples; e.g., Hispanic females.

The HRS includes the states of respondents in each December from 1992 to 2011. As the HRS interviews are usually conducted midyear, the state in December 2012 is not observed for most observations, and is thus dropped from the analysis. December 1992-December 1996 is used as the reference period, and corresponds to transitions 
in the 1993-1997 period. Three dummy variables were included that correspond to the 1998-2002, 2003-2007, and 2008-2011 periods, respectively. The 1998-2002 period includes the 2001 recession (Hall, 2007), while the 2008-2011 period covers the most recent recession. This period starts with December 2007, or at the point in time that is usually seen as marking the beginning of the recession (Goodman and Mance, 2011).

\subsection{Correction of mortality estimates}

In some cases, the survival probabilities estimated using the HRS are higher than those in the vital statistics. For example, for 2008-2011 the unadjusted life expectancy of women aged 50 is 36.6 years, while the equivalent figure for 2010 reported by the Centers for Disease Control (CDC) is 33.2 years (Arias, 2014). The direction of the difference is not unexpected, because poor health status may correlate with non-response. But as the magnitude of the gap is non-negligible, we had to correct it before we could make population-level estimates of working life expectancies. We did this by matching the survival probabilities with the CDC life tables.

Using external data on survival is common in the construction of working life tables (Smith, 1986; Skoog and Ciecka, 2010). In contrast to earlier studies, in which it was assumed that survival does not vary by labor force state or education, we match life expectancy by gender and race/ethnicity with CDC life tables, while allowing for variation by education and labor force status. The basic idea of the approach is that if survival probabilities by age, gender, and race are averaged over all labor force states and potentially educational level they should equal survival probabilities obtained from the CDC. To achieve this, we first calculated these averages and compared them to the CDC life tables. These comparisons are used to calculate scaling factors, which are used increase or decrease the survival estimates obtained from the HRS. A detailed explanation is given in the appendix.

This procedure was applied to all working life tables. Figure 2 illustrates the educational gradient in survival for the period 2008-2011, obtained using the full HRS sample and after matching. Higher education is found to be associated with longer life among both men and women, with the exception of males in their early to mid-fifties, for whom our results show no educational differences. This is caused by our mortality correction algorithm (see appendix). As mortality for these ages is low, it does not affect our main findings. Appendix table B8 shows the racial/ethnic survival gradient by level of education and over time. The results are consistent with those of prior literature, which showed that there are racial/ethnic differences at each educational level, and that survival is improving for all groups except for whites with low education (Brown et al., 2012; Hendi, 2015; Sasson, 2016).

\subsection{Weighting and resampling}

For all calculations we use the survey weights of the HRS. As weights are only provided for survey years and not for the years between surveys, we use weights of survey year $t$ for year $t+1$ as well. To estimate confidence intervals, we apply a bootstrap procedure suggested by Cameron and Trivedi (2005). We resample individual working life trajectories, thereby mimicking the complex sampling process 


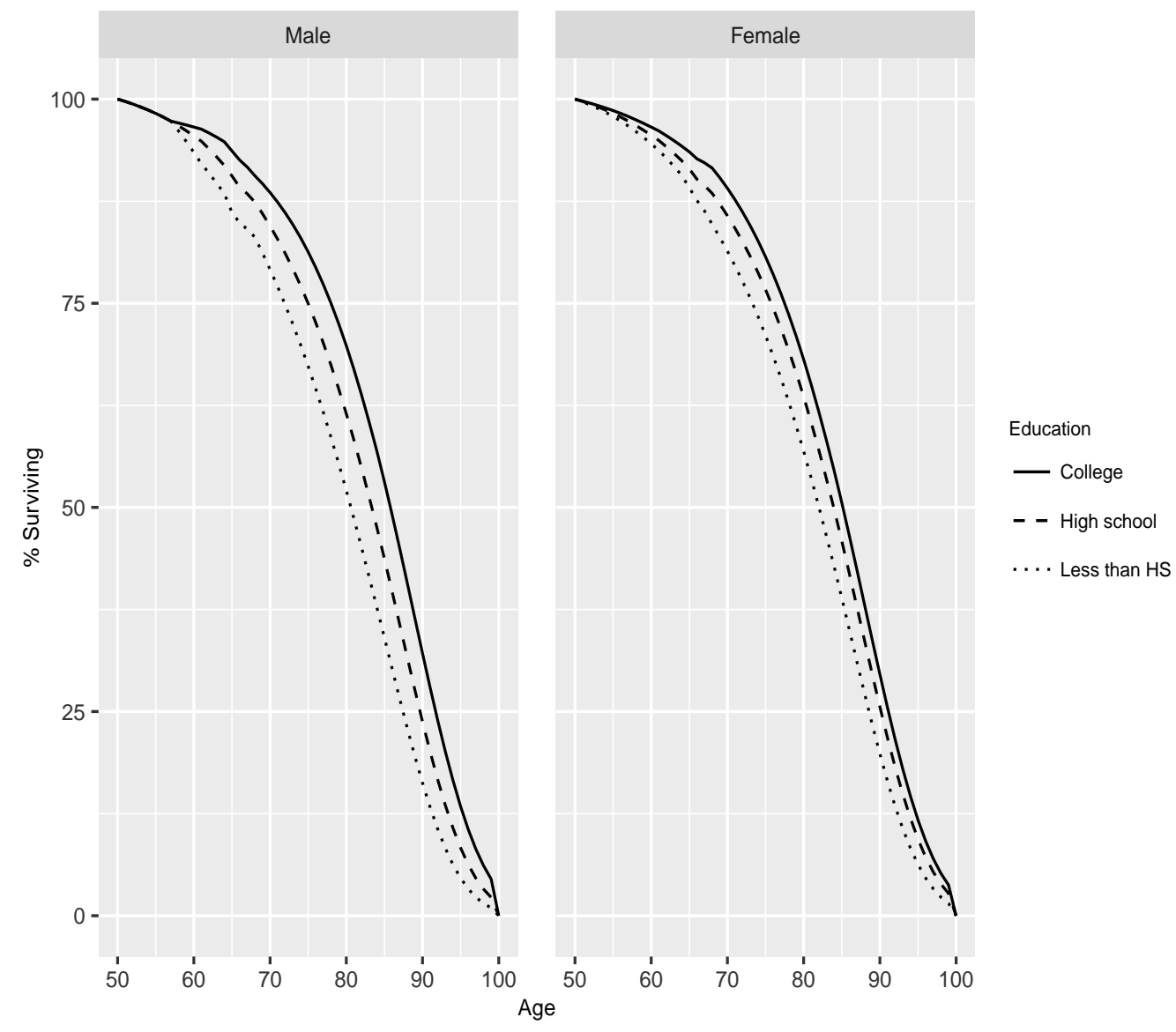

Figure 2: Life table survivor functions by education and gender, 2008-2011. Source: Own calculations based on the Health and Retirement Study, years 1992-2012.

of the HRS and accounting for both the cohort structure and oversampling in the HRS. A total of 1,000 bootstrap replications are used to derive percentile bootstrap confidence intervals. Testing relies on $95 \%$ confidence intervals of differences.

\section{Results}

\subsection{Transitions and transition probabilities}

Table 1 describes the data. We use data on 30,096 respondents. The number of transitions is 284,478 . Two-thirds of the respondents are white, $17 \%$ are black, and 9\% are Hispanic. Of the sample, roughly half have high school education, about one-quarter have college education, and another one-quarter have less than high school education. The distribution of the number of transitions by sex, race/ethnicity, and education closely matches the number of observations. The number of transitions by type of transitions shows that most of the time, people retain the labor force status they reported the previous year. When this state changes, the individuals who had had been employed or outside the labor force are most likely to retire (7\% and $13 \%$ of the transitions, respectively), while those who had been retired are most likely to die (4\%). Importantly, however, significant shares of the individuals who are retired 


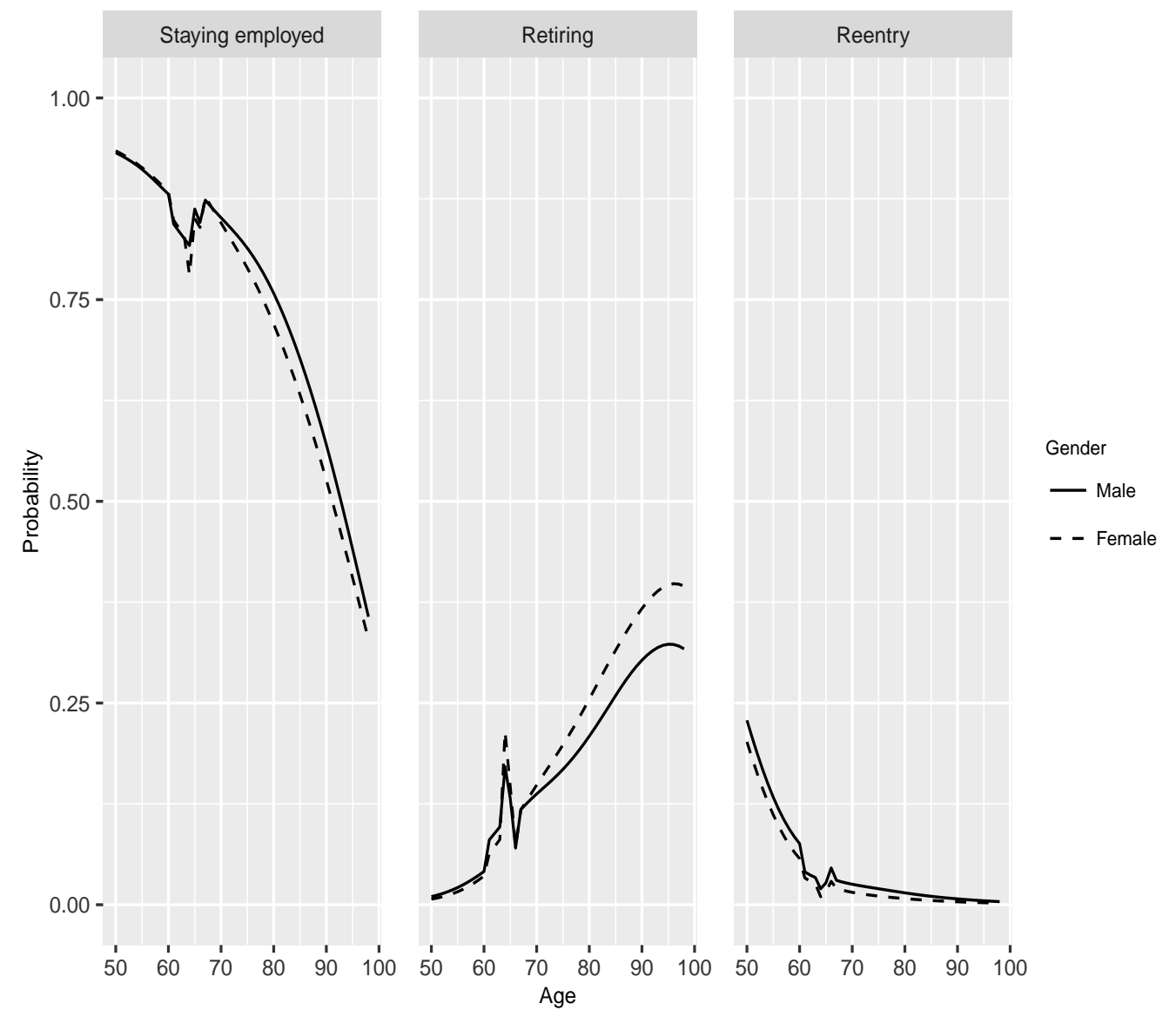

Figure 3: Age-specific probabilities of staying employed, retiring, and reentry to the labor market for males and females; 2008-2011. Source: Own calculations based on the Health and Retirement Study, years 1992-2012.

or are outside of the labor force re-enter employment ( $2 \%$ and $10 \%$ of the transitions, respectively), which demonstrates that retirement is not a straightforward transition.

Figure 3 gives an overview of the age schedule of selected transition probabilities by gender for the period 2008-2011. Panel A shows that the probability of staying employed was declining with age. Up to age 60 leaving employment mostly meant either becoming inactive or unemployed. While older women had a lower level of labor force attachment than men and a higher probability of becoming inactive, their probability of becoming unemployed was lower than that of men during the Great Recession (Sahin et al., 2010), which may explain the similar levels of employment exits of males and females for this age group. Sharp declines in the probability of staying employed could be observed among individuals aged 61 to 67 , with the sharpest drop occurring at age 64; thus, a high proportion of the individuals who were employed at age 64 were out of employment at age 65 .

The high probability of exiting employment at age 64 was mirrored by the probability of transitioning to retirement (Panel B), which peaked at age $64 .{ }^{1}$ This result is in line with that of previous studies, which found that it is still common

\footnotetext{
${ }^{1}$ The probability of retiring was calculated by averaging the probabilities for employed individuals and individuals out of the labor force using weights, as described in the previous section.
} 
Table 1: Number of observations and transitions by race/ethnicity and gender, education and gender, and by type of transition.

\begin{tabular}{|c|c|c|c|c|c|}
\hline & & Respondents & $\%$ & Transitions & $\%$ \\
\hline \multirow[t]{4}{*}{ Male } & White & 9,590 & 32 & 93,905 & 33 \\
\hline & Black & 1,992 & 7 & 15,147 & 5 \\
\hline & Hispanic & 1,235 & 4 & 9,739 & 3 \\
\hline & Other & 348 & 1 & 2,552 & 1 \\
\hline \multirow[t]{4}{*}{ Female } & White & 11,868 & 39 & 121,084 & 43 \\
\hline & Black & 3,048 & 10 & 25,395 & 9 \\
\hline & Hispanic & 1,604 & 5 & 13,457 & 5 \\
\hline & Other & 411 & 1 & 3,199 & 1 \\
\hline Total & & 30,096 & 100 & 284,478 & 100 \\
\hline \multirow[t]{3}{*}{ Male } & Less than high school degree & 3,483 & 12 & 30,662 & 11 \\
\hline & High school & 6,305 & 21 & 58,366 & 21 \\
\hline & College & 3,377 & 11 & 32,315 & 11 \\
\hline \multirow[t]{3}{*}{ Female } & Less than high school degree & 4,548 & 15 & 42,242 & 15 \\
\hline & High school & 9,007 & 30 & 90,125 & 32 \\
\hline & College & 3,376 & 11 & 30,768 & 11 \\
\hline Total & & 30,096 & 100 & 284,478 & 100 \\
\hline \multirow[t]{5}{*}{ Employed } & to employed & - & & 88,290 & 88 \\
\hline & to retired & - & & 7,517 & 7 \\
\hline & to out of LF & - & & 4,331 & 4 \\
\hline & to dead & - & & 602 & 1 \\
\hline & Total & - & & 100,740 & 100 \\
\hline \multirow[t]{5}{*}{ Retired } & to employed & - & & 2,913 & 2 \\
\hline & to retired & - & & 142,377 & 94 \\
\hline & to out of LF & - & & 1,129 & 1 \\
\hline & to dead & - & & 5,412 & 4 \\
\hline & Total & - & & 151,831 & 100 \\
\hline \multirow[t]{5}{*}{ Out of LF } & to employed & - & & 3,304 & 10 \\
\hline & to retired & - & & 4,287 & 13 \\
\hline & to out of LF & - & & 23,891 & 75 \\
\hline & to dead & - & & 425 & 1 \\
\hline & Total & - & & 31,907 & 100 \\
\hline
\end{tabular}

Source: Own calculations based on the Health and Retirement Study, years 1992-2012. 
for people to retire at age 65 (Coe et al., 2013; Behagel and Blau, 2012). Among individuals above age 70 the probability of staying employed declined sharply, while the probability of retiring increased steadily. In both cases males exhibited higher labor force attachment than females.

Panel $\mathrm{C}$ shows that the probability of returning to employment after retiring, which was high among relatively young retirees (Cahill et al., 2011), but declined with age, with a sharp drop occurring at age 65. This may be because large numbers of people retire at age 65 , and newly retired individuals seldom re-enter the work force immediately (Hayward et al., 1994).

\subsection{Working life expectancy}

Table 2 shows the WLE and the proportion of remaining life expectancy at age 50 that is spent working (relative WLE) by gender, race/ethnicity, and education. More detailed results, including estimates of remaining life expectancy are given in the appendix. Figures 4 and 5 illustrate the results by race/ethnicity (Figure 4) and education (Figure 5).

In 1993-97, the average WLE was 14.3 years for men and 11.4 years for women. These figures represent $53.5 \%$ and $36.5 \%$ of the total remaining life expectancy. Working life expectancy fluctuated for both men and women over the observation period, decreasing by approximately one year in the period 1998-2002, then bouncing back in the 2003-07 period. In the 2008-2011 period, which captures the Great Recession, WLE for men fell below the levels observed in any other period, to 12.7 years; while WLE for women declined less sharply, to 11 years. As total life expectancy increases for both men and women, the fraction of remaining life at age 50 that is spent working can decline without a proportional increase in working life expectancy. Indeed, the fraction of remaining years spent working at age 50 decreased between 1993-1997 and 2008-2011 from 53.5\% to $42.9 \%$ for men, and from $35.1 \%$ to $31.8 \%$ for women. The smaller decline for women may be attributed to the fact that the recession had a smaller impact on women than on men, and that remaining life expectancy at age 50 increased at a slower pace for females than for males. These patterns are similar for most educational and racial/ethnic groups, albeit at different levels.

\subsection{Working life expectancy by race/ethnicity and gender}

Results on working life expectancy by race/ethnicity and gender are shown in figure 4. Detailed results are given in the appendix. An overview of which comparisons are statistically significant at the $5 \%$ level is given in table 3 .

Looking at figure 4 , it is clear that that there are marked racial/ethnic differences in WLE. White males have the highest WLE across all observation periods, while Hispanic females have the lowest WLE in most periods. ${ }^{2}$ The difference in WLE between these two groups is up to 6.7 years, while the largest difference between

\footnotetext{
${ }^{2}$ Results for Hispanics may be influenced by selective migration, as individuals in poor health have a higher probability of returning to their country of origin than those in good health (Turra and Elo, 2008). However, for WLE this effect is likely to be small, as it should mostly affect people at older ages (Palloni and Arias, 2004).
} 


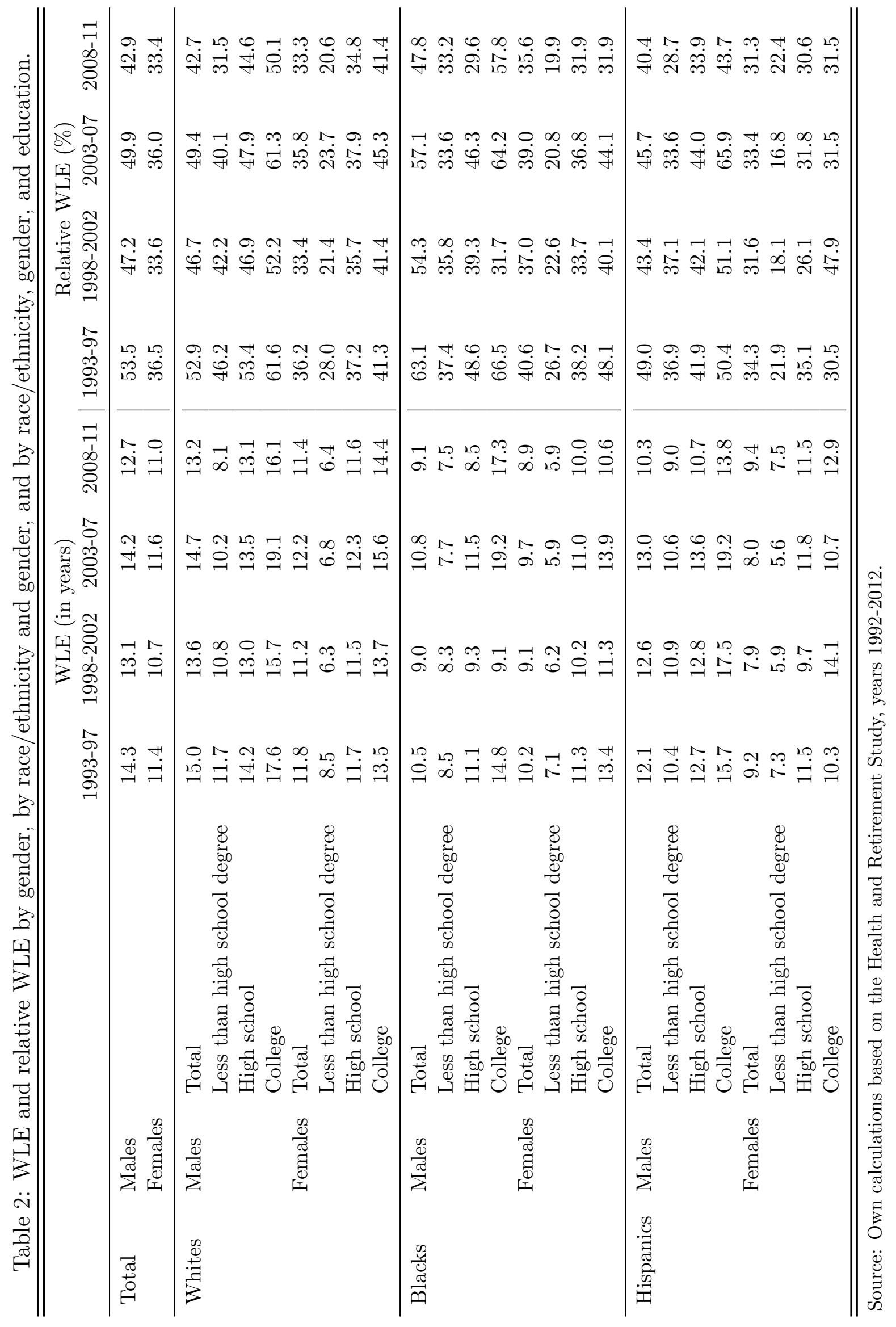




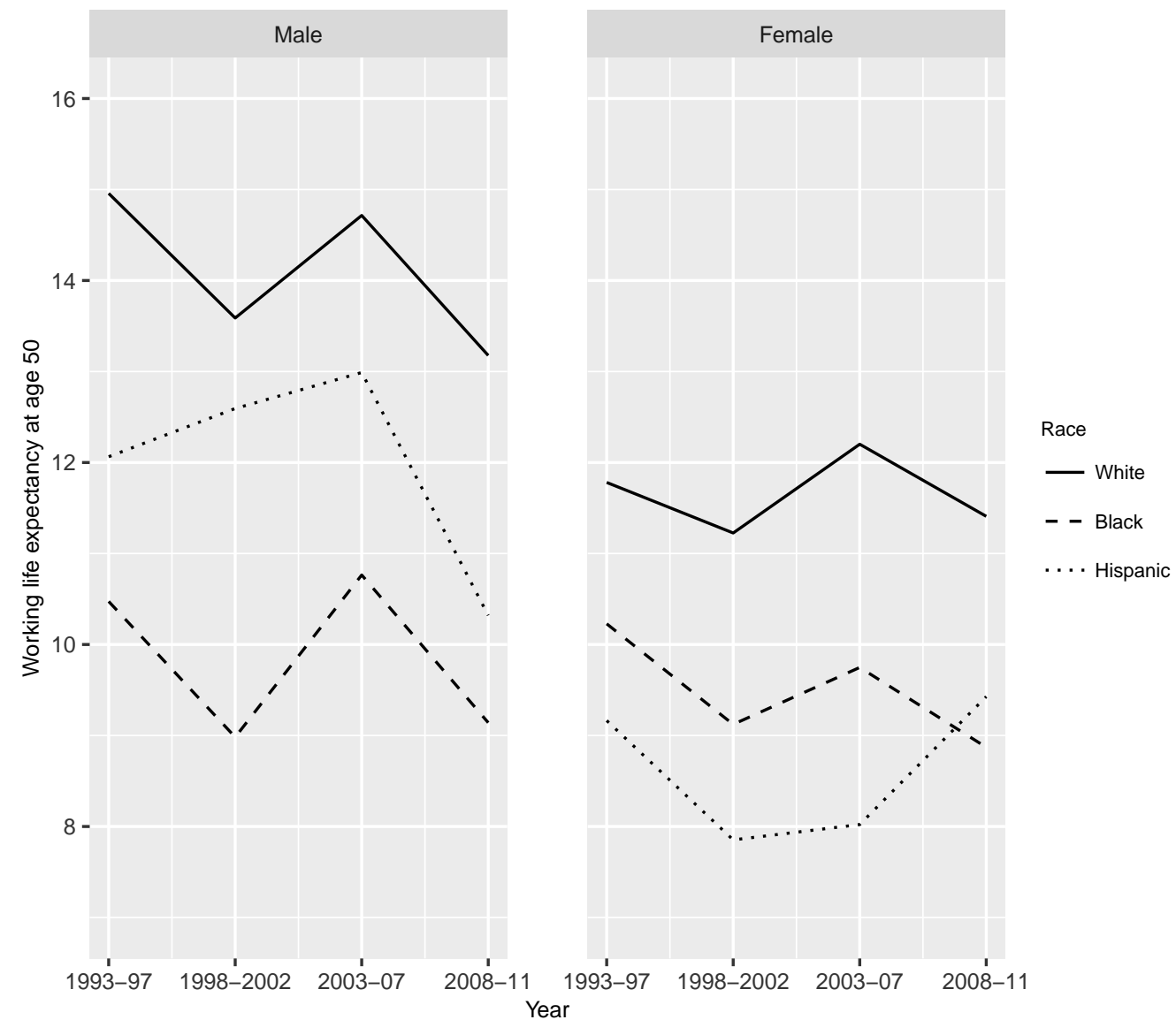

Figure 4: Working life expectancy at age 50 by race/ethnicity and gender. Source: Own calculations based on the Health and Retirement Study, years 1992-2012.

white males and females is considerably smaller, at about 3.2 years. Black males and females have a low WLE, but the gender differences among blacks are not as strong as they are among whites and Hispanics, and - unlike among whites and Hispanics - the gender differences are not statistically significant. WLE is also significantly higher for white males than for black males. A similar pattern emerges for the differences between white males and Hispanic males, except for the period of 1998-2002. The differences in the level of WLE by race/ethnicity are always significant for females.

For both white males and females there is no clear trend in WLE, and the differences between years seem to be mostly driven by period effects, which affect both males and females. The decreases from 1993-1997 to 1998-2002, and in particular from 2003-2007 to 2008-2011, were smaller for females than for males (0.8 for females vs. 1.5 for males). These results are in line with findings that show that the recessions in 2001 and 2007-2009 had a more severe impact on males than on females (Wood, 2014).

While the results for blacks show patterns of increase and decrease similar to those of whites, the results for Hispanics show very different patterns. For Hispanic males, WLE increased 0.4 years between 1993-1997 and 1998-2002 and 0.5 years between 1998-2002 and 2003-2007, while WLE decreased 2.7 years between 2003-2007 and 2008-2011. For Hispanic women, by contrast, WLE increased 1.4 years between 2003- 
Table 3: Comparison of levels of WLE by race/ethnicity and gender. Comparisons for which the $95 \%$ confidence intervals of WLEs do not overlap are marked with an asterisk.

\begin{tabular}{llcccc}
\hline \hline & & $1993-97$ & $1998-2002$ & $2003-07$ & $2008-11$ \\
\hline Male/female & White & $*$ & $*$ & $*$ & $*$ \\
& Black & & & & \\
& Hispanic & $*$ & $*$ & $*$ & \\
\hline White/black & Male & $*$ & $*$ & $*$ & $*$ \\
& Female & $*$ & $*$ & $*$ & $*$ \\
White/Hispanic & Male & $*$ & & $*$ & $*$ \\
& Female & $*$ & $*$ & $*$ & $*$ \\
\hline \hline
\end{tabular}

Source: Own calculations based on the Health and Retirement Study, years 1992-2012.

2007 and 2008-2011, even as it decreased for all other groups. Moreover, the gender differences in WLE between 2003-2007 and 2008-2011 were statistically significant for Hispanics, but not for whites and blacks. These results are consistent with the findings of Engemann and Wall (2009), who argued that the gender differences in the effects of the Great Recession have been more pronounced among Hispanics, and that female Hispanics were not strongly affected.

\subsection{Working life expectancy by education and gender}

Figure 5 shows that there is a clear educational gradient in WLE, whereby individuals with a college or university degree have the highest WLE, while those with less than a high school degree have the lowest WLE. All of these differences are statistically significant at the 5\% level. For each educational level, males have a higher WLE than females. Most of these differences are statistically significant, except for the period of 2008-2011, during which the gender gap was not significant for individuals with less than a high school degree and for individuals with a high school degree. Apart from these similarities, we see marked differences between educational groups. While the gender gap in WLE has been closing for both individuals with high school education and individuals with less than a high school degree, it has been highly volatile for individuals with a college degree.

Over the study period, WLE was volatile among individuals with college education, especially among males. For example, the WLE of males with a college degree increased 3.7 years between 1998-2002 and 2003-2007, and decreased 3.2 years thereafter. The changes were less pronounced for females with college education, a finding that further confirms the assumption that females have been less affected by the Great Recession than males (Wood, 2014).

The changes in WLE among males and females with high school education roughly matched those among individuals with a college degree, but the fluctuations were not as pronounced. For instance, among males with high school education WLE declined just 0.8 years between 2003-2007 and 2008-2011. While WLE among males with less than a high school degree decreased steadily, the difference between 2003-2007 and 2008-2011 amounted to 1.4 years, and was thus considerably smaller than the 


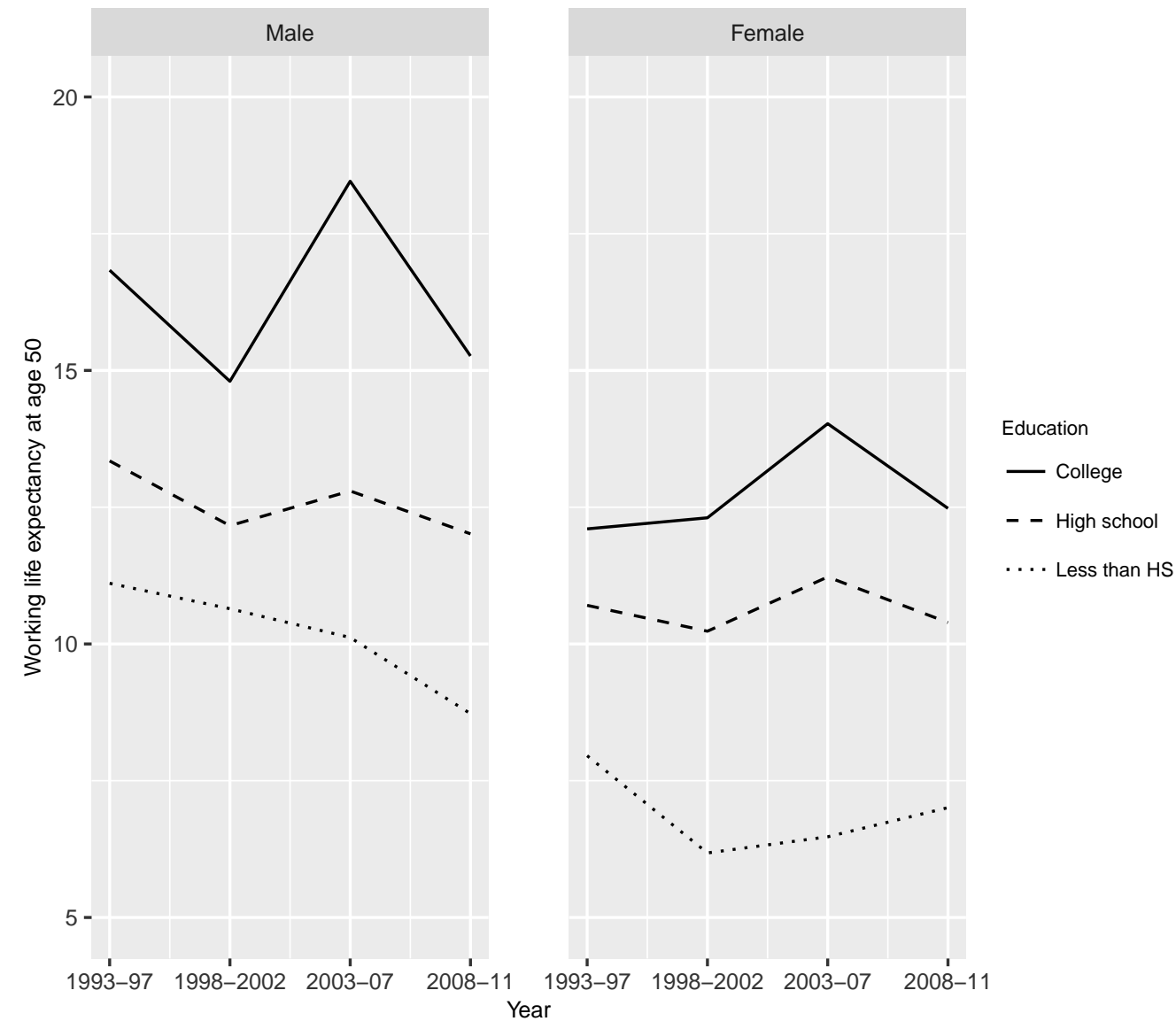

Figure 5: Working life expectancy at age 50 by education and gender. Source: Own calculations based on the Health and Retirement Study, years 1992-2012.

decline among males with college education. WLE among females with less than a high school degree actually increased 0.5 years during this period. This result is quite remarkable, as there is a general consensus that individuals with low levels of education have been more affected by the recent recession than others (Engemann and Wall, 2009; Coile and Levine, 2011). A potential explanation for this finding is the added worker effect: women with less than a high school degree may have (re-)joined the labor force to compensate for the job loss of a partner.

\subsection{Working life expectancy by race/ethnicity, gender, and education}

The results that combine all three variables under study partly mirror the findings already discussed above. Generally, whites had a higher WLE than blacks and Hispanics, and WLE increased with educational attainment. However, there were also important differences in WLE by race/ethnicity and gender when conditioned on education (table 4). For white and Hispanic males, the differences were of mixed signs and magnitudes. At the beginning of the observation period, there were relatively large differences between white and black males, with white males having a higher WLE at all educational levels; but by 2008-2011, the differences between white 
Table 4: Differences in WLE by educational attainment by gender and race/ethnicity. Differences which are statistically significant at the $5 \%$ level are marked with an asterisk.

\begin{tabular}{llrrrr}
\hline \hline & & $1993-97$ & $1998-2002$ & $2003-2007$ & $2008-11$ \\
\hline \multirow{2}{*}{ White/black females } & Less than HS & 1.5 & 0.1 & 0.9 & 0.5 \\
& HS & 0.4 & 1.3 & 1.3 & 1.6 \\
& College & 0.1 & 2.4 & 1.7 & $3.8^{*}$ \\
White/Hispanic females & Less than HS & 1.2 & 0.5 & 1.2 & -1.1 \\
& HS & 0.2 & 1.7 & 0.5 & 0.1 \\
& College & 3.1 & -0.4 & $4.9^{*}$ & 1.4 \\
\hline \multirow{2}{*}{ White/black males } & Less than HS & $3.2^{*}$ & $2.5^{*}$ & 2.5 & 0.6 \\
& HS & $3.1^{*}$ & $3.7^{*}$ & 2.0 & $4.6^{*}$ \\
\multirow{5}{*}{ White/Hispanic males } & College & 2.8 & $6.7^{*}$ & -0.1 & -1.3 \\
& Less than HS & 1.3 & -0.1 & -0.5 & -0.9 \\
& HS & 1.5 & 0.2 & -0.1 & 2.4 \\
& College & 2.0 & -1.8 & -0.1 & 2.3 \\
\hline \hline
\end{tabular}

Notes: HS=High school.

Source: Own calculations based on the Health and Retirement Study, years 1992-2012.

and black males with college and less than high school education had disappeared. The differences in WLE between whites and Hispanics also disappeared during the observation period. But because the sample size of blacks with a college degree is small, the results for this educational level should be viewed with care.

White females had a higher WLE than black or Hispanic females, irrespective of educational level or year; although the differences were often small and not significant, especially for those with less than a college degree. These findings are line with the results of Millimet et al. (2003, table 5), which indicated that the differences between white and non-white women aged 50 were negligible.

\subsection{The differential contributions of mortality and employ- ment to differences in WLE}

Differences in WLE are driven by differentials in the likelihood of being and staying employed if alive, and in the probability of being alive. For some comparisons, the differentials in mortality and in the probability of being employed reinforce each other; whereas for other comparisons, they may work in the opposite direction. We therefore analyze for selected key contrasts to what extent the observed differences are attributable to probabilities of employment, and to what extent they are attributable to mortality rates. In this analysis we focus on the 2008-2011 period and on comparisons across sub-populations, because within-population trends are almost exclusively driven by changes in labor force participation patterns, not by changes in mortality.

As our results depend not only on survival and transition probabilities, but also on the weights described in the methods section, we proceeded in the following fashion. For each comparison one set of weights was used for all sub-populations, and the differences between groups were recalculated. These recalculated differences 
Table 5: Results of the decomposition of gender gaps by race/ethnicity, racial/ethnic differences by gender, and educational differences by gender; 2008-2011.

\begin{tabular}{llrrrr}
\hline \hline \multirow{2}{*}{ Male/female } & & Total & Same weights & Mortality & Transitions \\
& White & 1.8 & 1.2 & -0.5 & 1.7 \\
& Black & 0.3 & 0.1 & -0.5 & 0.5 \\
& Hispanic & 0.9 & 0.0 & -0.2 & 0.2 \\
\hline White/black & Males & 4.0 & 3.1 & 0.6 & 2.5 \\
& Females & 2.5 & 1.9 & 0.3 & 1.7 \\
White/Hispanic & Males & 2.9 & 2.4 & -0.2 & 2.6 \\
& Females & 2.0 & 1.1 & -0.2 & 1.2 \\
\hline College/less than HS & Males & 6.5 & 6.1 & 1.1 & 5.0 \\
& Females & 5.5 & 5.0 & 0.3 & 4.6 \\
College/HS & Males & 3.3 & 3.0 & 0.6 & 2.5 \\
& Females & 2.1 & 2.0 & 0.2 & 1.8 \\
\hline \hline
\end{tabular}

Notes: HS=High school.

Source: Own calculations based on the Health and Retirement Study, years 1992-2012.

showed to what degree the labor force status composition of each group at age 50 influenced these differences. In a second step, using the method developed by Kitagawa (1955), we decomposed the differences based on the same weights into two parts: the contribution of transition probabilities and the contribution of survival probabilities.

The results are shown in table 5. The first column gives the differences in WLE for our original analysis. For instance, the 1.8-year difference between white males and females resulted from WLEs of 13.2 years and 11.4 years, respectively (see table 2 ). The second column gives WLE recalculated using the same weights for both of the compared groups, whereby we always used the weights of the group given first in the table. For the comparison of white males and females, the first group was made up of white males, and the recalculated difference was 1.2. Columns 3 and 4 decompose this recalculated difference into the part due to mortality and the part due to differences in the transitions between labor force states.

The decomposition of gender gaps by race/ethnicity shows that the differences for blacks and Hispanics are, at first glance, due to composition, and that the reweighted differences are close to zero. But these results mask a negative contribution of mortality due to the higher life expectancy of women, and a positive contribution of transitions, which more or less cancel each other out. The effect of mortality is found to be qualitatively similar for whites and for blacks, but the effect of labor force transitions is shown to be higher for whites than for blacks. If white males had the same mortality patterns as white females, the re-weighted difference would have increased from 1.2 years to 1.7 years.

The largest share of racial/ethnic differences by gender is due to differences in transition probabilities between labor force states, which in all cases made a positive contribution. A comparison of the original and the re-weighted estimates of WLE shows that there were also composition effects, whereas the contribution of mortality 
was small compared to the overall difference. This is attributable to the fact that for all of the groups compared, mortality was relatively low at ages with high levels of labor force attachment, and that this contribution to WLE was large.

The educational differences were also mostly driven by the contribution of transition probabilities. However, in contrast to the racial/ethnic differences within sexes, mortality made consistently positive contributions to the WLE differences, thus reinforcing the impact of labor force participation differences.

\section{Discussion}

\subsection{Main findings}

The Great Recession has had a strong negative impact on the work expectancy patterns of older individuals. Despite recent declines in working life expectancy, American men who have reached age 50 still spend 13 years, or more than two-fifths of their remaining life, working; and 50-year-old American women work 11 years, or one-third, of their remaining life. Although adverse labor market conditions seem to have outweighed the incentives to stay in the labor force longer for the US population as a whole, our findings also show that there is considerable heterogeneity across sub-populations. These results are consistent with the findings from the emerging literature on the effects of the crisis on sub-populations.

Our results suggest that in international comparison, US working life expectancy levels are relatively high. These levels have fluctuated over the last 20 years, and show no clear trend. In 2008-2011 in the US, WLE at age 50 was 13 years for men and 11 years for women. Butt et al. (2008) estimated for the UK that working life expectancy at age 50 in 1998-2003 was 10 years for men and seven years for women. Leinonen et al. (2016b) reported for Finland that working life expectancy at age 50 in the year 2012 was nine years for men and 10 years for women. However, as life expectancy has been increasing in the US but working life expectancy has not, the fraction of remaining years at age 50 that are spent working has declined among men, from more than $54 \%$ in the early 1990s to $43 \%$ in 2008-2011. Among women, this share has fallen from 37\% to 33\%. Despite these declines, 50-year-old Americans can still expect to spend a comparatively large fraction of their remaining life working. In the UK the fractions of remaining life at age 50 in the period 1998-2003 were $35 \%$ for men and $22 \%$ for women, and in Finland in 2012 the fractions of remaining life at age 50 were $31 \%$ for men and $29 \%$ for women.

We found that while the variation in working life expectancy by racial/ethnic groups has been large, it shows signs of changing. Over the 20-year observation period from 1992 to 2012, the working life expectancy of men at age 50 was consistently around five years lower among blacks than among non-Hispanic whites. Among Hispanics, working life expectancy was in between the WLE values of the other two groups. Among women, however, blacks had a working life expectancy that was only around two years lower than that of non-Hispanic whites. In the 15 years prior to the Great Recession, from 1992 to 2007, black women also had higher working life expectancy levels than Hispanic women. However, this differential was reversed in 2008-2011, as Hispanic women caught up with black women.

Racial/ethnic differentials in working life expectancy are mostly due to differences 
in transition probabilities (staying employed, returning to the labor market. retiring, etc.). The differences between blacks and whites might be explained by the relative disadvantages of blacks and discrimination against blacks in the labor market (Altonji and Blank, 1999; Pager, 2009). Moreover, blacks are, on average, less healthy, and have a higher risk of being disabled than whites, which is reflected in a lower active life expectancy (Hayward and Heron, 1999). The finding that Hispanics have a markedly lower working life expectancy than non-Hispanic whites cannot be explained by health, as Hispanics compare favorably to blacks and whites in terms of both health and life expectancy (Lariscy et al., 2015). Indeed, our decompositions suggest that mortality contributes negatively to - i.e., narrows - working life expectancy differences between whites and Hispanics, and that the working life expectancy differential is fully explained by lower levels of labor market attachment among the Hispanic population.

Of the groups studied, the Great Recession had the strongest negative impact on working life expectancy among male Hispanics, while Hispanic females experienced an increase in working life expectancy in 2008-2011. This differential impact by sex among Hispanics is consistent with the findings of early analyses by Engemann and Wall (2009), which indicated that the decline in employment has been particularly small among Hispanic women. It is possible that as the labor force participation of female Hispanics had been relatively low, there was a large potential for the added worker effect, whereby inactive individuals enter the labor market when their partner or spouse becomes unemployed (Starr, 2014).

Educational differences in WLE were found to be large and persistent. Among men in 2008-2011, those with college education could expect to have 16 more working years, while those with less than high school education could expect to have only eight years. Among women the differential was similar, from 14 to six years. The direction of the differential is not surprising given the well-known educational differences in labor market opportunities, health (Crimmins and Saito, 2001; Dupre, 2008), and life expectancy (Montez et al., 2011; Olshansky et al., 2012). However, our decompositions show that mortality contributes relatively little (less than 20\%) to the educational differences in WLE, and that the remainder of the differences are attributable to weaker labor force attachment among the less educated.

We found a strong negative impact of the Great Recession on working life expectancy for those with college education. This result is unexpected, but may be due to the fact that these individuals have a higher probability of retiring if they become unemployed than other groups, possibly because they can more easily afford leave the labor force. Indeed, additional calculations show that the probability that a 50-year-old employed male would be retired at age 65 increased considerably for males with a college degree: conditional on surviving, the probability was $34 \%$ in 2003-2007, while it was $46 \%$ in 2008-2011. For males with a high school degree and no degree, the probability increased by five percentage points and four percentage points, respectively. For women, the differentials were qualitatively similar, with the differences between 2008-2011 and 2003-2007 amounting to 7\% (college), 4\% (high school), and 1\% (less than high school).

Our findings are largely consistent with earlier findings on working life expectancy in the US. Smith (1986) estimated the working life expectancy at age 50 to be 12.3 years for men and 9.8 years for women in the 1979-1980 period. This estimate for 
women is lower than our estimates, which are between 10.7 and 11.6 years, but the Smith paper covers an earlier period in which female labor force participation was lower. The findings of Millimet et al. (2003, 2010), which cover the period from 1992 to 2000, are on a different level than our estimates for the period 1993-1997, because they use a different definition of working life expectancy. But these findings are qualitatively similar with respect to the differences between groups. For instance, they found that non-whites males had a lower WLE than white males, while the differences between white and non-white females were small. Skoog and Ciecka (2010) estimated the working life expectancy at age 50 to be 13.1 years for men. This estimate is close to our estimates, but they also used another definition of working life expectancy, and focused on labor force activity instead of employment.

It is worth noting that although the variation in working life expectancy by level of education and race is very large in the US, even the sub-populations with low working life expectancies tend to have higher WLEs than people in other countries. In 2012 in Finland, male working life expectancy at age 50 was 9.1 years (Leinonen et al., 2016b). White, black, and Hispanic men in the US in 2008-2011 all had a working life expectancy of at least 9.1 years, and often higher. Across educational groups, only those individuals with less than high school education had less than 9.1 years of working life expectancy. For women, working life expectancy among sub-populations, as defined by race, was close to the Finnish average of 10 years (Leinonen et al., 2016b). White females had a working life expectancy that was higher, while blacks and Hispanics had a WLE that was one year lower than the Finnish average. Females with high school education also had a WLE close to Finnish females, while females without a degree and females with a college degree, respectively, were 3 years below and 2.5 years above female Finns.

\subsection{Methodological considerations}

A key feature of our analysis is that we focus on working life expectancy, not on retirement age. If we had used retirement age as a proxy for the length of working life, we would have reached different conclusions. For the US, the OECD (2015a) reports that the average effective age at retirement in 2014 was 65.9 for men and 64.7 for women. The average effective retirement age declined steadily from 68 years (men and women) in 1970 to 64 (men) and 63 (women) years in the early to mid-1990s (Gendell and Siegel, 1996), and has since been increasing, with small fluctuations. For example, for men the reported average effective retirement age was 64.3 in 1995, 64.6 in 2005, 65.6 in 2010, and 65.9 in 2014. Importantly, these numbers do not suggest any significant effect of the Great Recession. If we assumed that individuals spend most of their time between reaching age 50 and retiring in employment, WLE would be roughly 14.3 years (2000), 14.6 years (2005), and 15.6 years (2010). By contrast, our WLE estimates for males without accounting for race/ethnicity or education amount to 13.1 years (2000), 14.2 years (2005), and 12.7 years (2010). While our estimates for 2005 are close to these values, the difference between the actual and the potential values for 2010 amounts to 2.9 years. For women the difference is even bigger, amounting to 4.3 years based on an average age at retirement of 65.3 years and a WLE estimate of 11.0 years. Retirement age is thus not a useful proxy for either the trends or the levels of WLE. 
There are some limitations to our analysis. First, our results are for individuals at age 50, and may not give a complete picture of working life expectancy over the whole life course. For example, our findings suggest that at age 50 working life expectancy is lower for individuals with no degree than for individuals with a high school or college degree. However, because members of the former group may enter the labor market earlier than members of the latter group, differences in total working life expectancy over the life course may be less pronounced. Second, the period perspective we have chosen allowed us to directly assess the demographic impact of the Great Recession by showing how individuals above age 50 would fare if transition probabilities remained constant; i.e., if the conditions of the recession prevailed not just for a few years, but over a period spanning old age. From a cohort perspective the impact will likely be less strong (Leinonen et al., 2016b). Third, we analyzed the differential levels in working life expectancy before and after the Great Recession, and interpreted the differential as the impact of the Great Recession. However, changes in working life expectancy may be caused not only by the crisis, but by other factors as well, such as policy changes or pre-existing trends in working life expectancy. While we cannot rule these other factors out, it seems unlikely that they contributed substantially to any of the key patterns we observed, such as the increase in WLE among female Hispanics and the decrease in WLE among male Hispanics.

\section{Conclusion}

Using data from the US Health and Retirement Study, we constructed period working life tables by gender, race/ethnicity, and education; and analyzed the impact of the Great Recession. We found strong differences by gender, race/ethnicity, and education. These differences were mostly driven by differences in transitions between labor force state, and not by differences in mortality. At age 50, men had a remaining working life expectancy that was approximately two years longer than that of women. Individuals with college education could expect to work more than two times longer than those with less than high school education, and non-Hispanic whites could expect to work more than one-third longer than blacks. However, these differences mostly disappeared if education was controlled for, with the exception of differences between white and black males. Gender gaps varied strongly by race. For example, except during the Great Recession, the gap between males and females was largest among Hispanics; whereas the gender differences were small among blacks.

Our findings point to the importance of gender and racial differences, the intersection of these differences, economic conditions, and the interaction of all of these factors in determining the length of working life. Trends over time show no clear expansion of working life, which seems problematic in light of population aging and increasing longevity. If the shares of the US population who earn a high school or a college degree continue to grow (Ryan and Bauman, 2016), average working life expectancy may increase, as these groups have comparatively high working life expectancy levels at age 50; however, this effect may be at least partially offset by later entry into the labor market. Another concern that has been raised is the heterogeneity of working life expectancy in general and the consistently low working life expectancy of some groups, particularly blacks and individuals with less than 
high school education. Policies that better address this heterogeneity may be needed. While racial differences can be partly explained by differentials in life expectancy and education, they are mostly due to differences in labor market performance. Moreover, a better understanding of how differences are shaped by inequalities in health, health behaviors, and disability is needed to design effective policies that encourage a productive prolongation of working life, without an accompanying compromise in well-being.

\section{References}

Altonji, J. G. and Blank, R. M. (1999). Race and gender in the labor market. In Ashenfelter, O. C. and Card, D. (eds), Handbook of Labor Economics. Elsevier, 3143-3259.

Arias, E. (2002). United States life tables, 2000, National Vital Statistics Reports 51.

Arias, E. (2014). United States life tables, 2010, National Vital Statistics Reports 63.

Arias, E., Rostron, B. L. and Tejada-Vera, B. (2010). United States life tables, 2005, National Vital Statistics Reports 58.

Behagel, L. and Blau, D. M. (2012). Framing social security reform: Behavioral responses to changes in the full retirement age. American Economic Journal: Economic Policy 4: 41-67.

Brown, D. C., Hayward, M. D., Montez, J. K., Hummer, R. A., Chiu, C.-T. and Hidajat, M. M. (2012). The significance of education for mortality compression in the united states. Demography 49: 819-840.

Bureau of Labor Statistics (2015). Employment status of the civilian noninstitutional population 25 years and over by educational attainment, sex, race, and Hispanic or latino ethnicity, http://www.bls.gov/cps/cpsaat07.pdf. Accessed 19 July 2016.

Butt, Z., Haberman, S. and Verral, R. (2008). Calculating compensation for loss of future earnings: estimating and using working life expectancy. Journal of the Royal Statistical Society, Series A 171: 763-805.

Cahill, K. E., Giandrea, M. D. and Quinn, J. F. (2011). Reentering the labor force after retirement, Monthly Labor Review, June 2011.

Cahill, K. E., Giandrea, M. D. and Quinn, J. F. (2015). Retirement patterns and the macroeconomy, 1992-2010: The prevalence and determinants of bridge jobs, phased retirement, and reentry among three recent cohorts of older Americans. The Gerontologist 55: 384-403.

Cameron, A. C. and Trivedi, P. K. (2005). Microeconometrics. Methods and Applications. Cambridge, M. A.: Cambridge University Press.

Coe, N. B., Khan, M. and Rutledge, M. S. (2013). Sticky ages: Why is age 65 still a retirement peak?, center for Retirement Research Working Paper 2013-2, Boston College.

Coile, C. C. and Levine, P. B. (2011). Recessions, retirement, and social security. American Economic Review: Papers 83 Proceedings 101: 23-28.

Colby, S. L. and Ortman, J. M. (2015). Projections of the size and composition of the U.S. population: 2014 to 2060, Washington, D.C.: U.S. Census Bureau.

Crimmins, E. M. and Saito, Y. (2001). Trends in healthy life expectancy in the United 
States, 1970-1990: Gender, racial, and educational differences. Social Science $\mathcal{G}_{3}$ Medicine 52: 16291641.

Dudel, C. (2016). The Health and Retirement Study job panel, Mimeo, Rostock.

Dupre, M. E. (2008). Educational differences in health risks and illness over the life course: A test of cumulative disadvantage theory. Social Science Research 37: $1253-1266$.

Engemann, K. M. and Wall, H. J. (2009). The effects of recessions across demographic groups, Federal Reserve Bank of St. Louis Working Paper 2009-052A.

Eurostat (2015). EUROPOP2013 - population projections at national level, available at http://ec.europa.eu/eurostat/data/database?node_code=proj. Accessed 19 July 2016.

Farber, H. S. (2011). Job loss in the Great Recession: Historical perspective from the Displaced Workers Survey, 1984-2010, NBER Working Paper 17040.

Flippen, C. and Tienda, M. (2000). Pathways to retirement: Patterns of labor force participation and labor market exit among the pre-retirement population by race, Hispanic origin, and sex. Journal of Gerontology: Social Sciences 55B: S14-S27.

Gendell, M. and Siegel, J. S. (1996). Trends in retirement age in the United States, 1995-1993, by sex and race. Journal of Gerontology 51B: S132-S139.

Goodman, C. J. and Mance, S. M. (2011). Employment loss and the 2007-09 recession: an overview, Monthly Labor Review, April 2011.

Greene, W. H. (2012). Econometric Analysis. Pearson, 7th ed.

Hall, R. E. (2007). How much do we understand about the modern recession? Brookings Papers on Economic Activity 2007/2: 13-28.

Hayward, M. D. and Grady, W. R. (1990). Work and retirement among a cohort of older men in the United States, 1966-1983. Demography 27: 337-356.

Hayward, M. D., Hardy, M. A. and Liu, M.-C. (1994). Work after retirement: The experiences of older men in the United States. Social Science Research 23: 82-107.

Hayward, M. D. and Heron, M. (1999). Racial inequality in active life among adult Americans. Demography 36: 77-91.

Hendi, A. S. (2015). Trends in U.S. life expectancy gradients: the role of changing educational composition. International Journal of Epidemiology 44: 946-955.

Hoem, J. M. (1977). A Markov chain model of working life tables. Scandinavian Actuarial Journal 1977: 1-20.

Hurd, M. D. and Rohwedder, S. (2010). The effects of the economic crisis on the older speculation, Michigan Retirement Research Center Working Paper 2010-231.

Jemal, A., Ward, E., Anderson, R. N., Murray, T. and Thun, M. J. (2008). Widening of socioeconomic inequalities in U.S. death rates, 19932001. PLoS ONE 3: e2181.

Juster, F. T. and Suzman, R. (1995). An overview of the Health and Retirement Study. Journal of Human Resources 30: S7-S56.

Kitagawa, E. M. (1955). Components of a difference between two rates. Journal of the American Statistical Association 50: 1168-1194.

Lariscy, J. T., Hummer, R. D. and Hayward, M. D. (2015). Hispanic older adult mortality in the United States: New estimates and an assessment of factors shaping the Hispanic paradox. Demography 52: 1-14.

Leinonen, T., Laaksonen, M., Chandola, T. and Martikainen, P. (2016a). Health as a predictor of early retirement before and after introduction of a flexible statutory pension age in Finland. Social Science $\&$ Medicine 158: 149-157. 
Leinonen, T., Martikainen, P. and Myrskylä, M. (2016b). Life expectancy by labor force status and social class: Recent period and cohort trends and projections for Finland. Journal of Gerontology, Series B: Psychological Sciences and Social Sciences Advance acess.

Marshall, V. W., Clarke, P. J. and Ballantyne, P. J. (2001). Instability in the retirement transition. effects on health and well-being in a Canadian study. Research on Aging 23: 379-409.

Meara, E. R., Richards, S. and Cutler, D. M. (2008). The gap gets bigger: Changes in mortality and life expectancy, by education, 1981-2000. Health Affairs 27: 350-360.

Millimet, D. L., Nieswiadomy, M., Ryu, H. and Slottje, D. (2003). Estimating worklife expectancy: an econometric approach. Journal of Econometrics 113: 83-113.

Millimet, D. L., Nieswiadomy, M. and Slottje, D. (2010). Detailed estimation of worklife expectancy for the measurement of human capital: Accounting for marriage and for children. Journal of Economic Surveys 24: 339-361.

Montez, J. K., Hummer, R. A., Hayward, M. D., Woo, H. and Rogers, R. G. (2011). Trends in the educational gradient of U.S. adult mortality from 1986 through 2006 by race, gender, and age group. Research on Aging 33: 145-171.

National Center for Health Statistics (1998). Vital statistics of the United States, 1995, Life tables.

Nurminen, M. M., Heathcote, C. R., Davis, B. A. and Puza, B. D. (2005). Working life expectancies: the case of Finland 1980-2006. Journal of the Royal Statistical Society, Series A 168: 567-581.

OECD (2013). Pensions at a glance 2013, http://www.oecd-ilibrary. org/finance-and-investment/pensions-at-a-glance-2013_pension_ glance-2013-en. Accessed 19 July 2016.

OECD (2015a). Ageing and employment policies - Statistics on average effective age of retirement, http://www.oecd.org/els/emp/ ageingandemploymentpolicies-statisticsonaverageeffectiveageofretirement . htm. Accessed 19 July 2016.

OECD (2015b). Pensions at a glance 2015, http://www.oecd.org/publications/ oecd-pensions-at-a-glance-19991363.htm. Accessed 19 July 2016.

Olshansky, S. J., Antonucci, T., Berkman, L., Binstock, R. H., Boersch-Supan, A., Cacioppo, J. T., Carnes, B. A., Carstensen, L. L., Fried, L. P., Goldman, D. P., Jackson, J., Kohli, M., Rother, J., Zheng, Y. and Rowe, J. (2012). Differences in life expectancy due to race and educational differences are widening, and many may not catch up. Health Affairs 31: 1803-1813.

Pager, D. (2009). Discrimination in a low-wage labor market. A field experiment. American Sociological Review 74: 777-799.

Palloni, A. and Arias, E. (2004). Paradox lost: Explaining the Hispanic adult mortality advantage. Demography 41: 385-415.

Ryan, C. L. and Bauman, K. (2016). Educational attainment in the United States: 2015, Current Population Reports, March 2016, US Census Bureau.

Sahin, A., Song, J. and Hobijn, B. (2010). The unemployment gender gap during the recent recession, Current Issues in Economics and Finance 16, Federal Reserve Bank of New York.

Sasson, I. (2016). Trends in life expectancy and lifespan variation by educational attainment: United States, 1990-2010. Demography 53: 269-293. 
Skoog, G. R. and Ciecka, J. E. (2010). Measuring years of inactivity, years in retirement, time to retirement, and age at retirement within the Markov model. Demography 47: 609-628.

Smith, S. J. (1986). Worklife estimates: Effects of race and education, Bureau of Labor Statistics Bulletin 2254.

Starr, M. A. (2014). Gender, added-worker effects, and the 2007-2009 recession: Looking within the household. Review of Economics of the Household 12: 209-235.

Turra, C. M. and Elo, I. T. (2008). The impact of salmon bias on the Hispanic mortality advantage: New evidence from social security data. Population Research and Policy Review 27: 515-530.

United Nations (2015). World population ageing 2015, highlights, Department of Economic and Social Affairs, http://www.un.org/en/development/desa/ population/publications/pdf/ageing/WPA2015_Highlights.pdf. Accessed 19 July 2016.

Wood, C. A. (2014). The rise in women's share of nonfarm employment during the 2007-2009 recession: a historical perspective, Monthly Labor Review April 2014.

Yee, T. W. and Wild, C. J. (1996). Vector generalized additive models. Journal of the Royal Statistical Society, Series B 58: 481-493. 


\section{A Mortality estimation and correction}

\section{A.1 Mortality estimation for Hispanics}

To adjust our survival estimates, we use CDC life tables for the years 1995 (National Center for Health Statistics, 1998), 2000 (Arias, 2002), 2005 (Arias et al., 2010), and 2010 (Arias, 2014) for the periods of 1993-1997, 1998-2002, 2003-2007, and 2008-2011, respectively. Because the CDC does not supply life tables for Hispanics for the years 1995, 2000, and 2005, we used the life tables for Hispanics for the years 2006 and 2010, and estimated the missing years by assuming that mortality differentials between Hispanics and whites and blacks for 2005/2006 and 2010 also prevailed in 1995 and 2000. More technically, the logarithm of age-specific probabilities of dying for the years 2005 and 2010 were used as a dependent variable in a linear regression, with a cubic age polynomial and log probabilities of dying of whites and blacks as explanatory variables. Regressions were run separately for males and females. These models exhibit good predictive qualities. For example, in the regression model for women $R^{2}$ is close to 1 and the relative prediction error is less than 0.01. Parameter estimates were used to estimate log probabilities of dying for the years 1995 and 2000 .

Before the regression approach outlined above could be applied another estimation step was needed, as the CDC life tables for whites and blacks for 1995 end with age 85. In this case also a regression approach was used to estimate probabilities of dying for ages 85 to 99. Log probabilities of dying for ages 85 to 99 of the years 2000, 2005, and 2010 were used as dependent variables. Explanatory variables included a cubic age polynomial and survival at age 85. Parameter estimates were used to estimate log probabilities of dying for 1995.

\section{A.2 Mortality correction: Matching with CDC life tables}

Matching mortality with CDC life tables works as follows. Let $p(x, e)=p(e \mid x, e)+$ $p(o \mid x, e)+p(r \mid x, e)$ denote the probability that an employed individual aged $x$ survives, where $e$ represents the labor force status employed, $o$ represents the status out of the labor force or unemployed, and $r$ represents the status retired. $p(x, o)$ and $p(x, r)$ denote the survival probabilities for individuals who are, respectively, out of the labor force and retired, and can be decomposed in a similar manner. These probabilities are estimated using HRS data as described in the main text. $p_{\mathrm{CDC}}(x)$ denotes the survival probability for age $x$ reported by the CDC. $d(x, e), d(x, o)$, and $d(x, r)$ denote the proportion of individuals at age $x$ who are, respectively, employed, out of the labor force or unemployed, and retired. Given a starting distribution for the youngest age $d_{S}(50, j)$, the proportions $d(x, j)$ for any age $x$ can be calculated by the repeated application of the transition probabilities.

Ensuring that the working life tables imply the same life expectancy as the life tables of the CDC requires that

$$
p(x, e) d(x, e)+p(x, o) d(x, o)+p(x, r) d(x, r)=p_{\mathrm{CDC}}(x)
$$

holds. This simply means that average survival follows the CDC life table. To achieve this, the following algorithm was applied, whereby $p_{\text {est }}$ is used to indicate estimated 
probabilities derived from the multinomial logit model, and $p_{\text {adj }}$ is used to denote adjusted values:

1. Set $d(50, e)=w_{e}(50), d(50, o)=w_{o}(50), d(50, r)=w_{r}(50)$, where $w_{j}(50)$ denotes the weights described in the methods section.

2. For each $x=50, \cdots, 98$ :

(a) Calculate

$$
a=\frac{p_{e s t}(x, e) d(x, e)+p_{e s t}(x, o) d(x, o)+p_{e s t}(x, r) d(x, r)}{p_{\mathrm{CDC}}(x)}
$$

(b) Calculate $p^{\prime}(x, j)=p_{e s t}(x, j) / a$ for $j=e, o, r$

i. If any $p^{\prime}(x, j)>1$ set $p_{a d j}(x, j)=p_{\mathrm{CDC}}(x)$ for $j=e, o, r$

ii. Else set $p_{a d j}(x, j)=p^{\prime}(x, j)$ for $j=e, o, r$

(c) Calculate

$$
b(j)=\frac{p_{e s t}(e \mid x, j)+p_{e s t}(o \mid x, j)+p_{e s t}(r \mid x, j)}{p_{a d j}(x, j)}
$$

for $j=e, o, r$

(d) Set $p_{a d j}(e \mid x, j)=p_{e s t}(e \mid x, j) / b, p_{a d j}(o \mid x, j)=p_{e s t}(o \mid x, j) / b$, and $p_{a d j}(r \mid x, j)=$ $p_{\text {est }}(r \mid x, \cdot) / b$ for $j=e, o, r$

(e) Set $d(x+1, j)=d(x, e) p_{a d j}(j \mid x, e)+d(x, o) p_{a d j}(j \mid x, o)+d(x, r) p_{a d j}(j \mid x, r)$ for $j=e, o, r$

3. Set $p_{a d j}(99, j)=0$ for $j=e, o, r$

Step 1 states that the algorithm starts with age 50 and sets the weights of each of the three states equal to its empirical proportion. $a$ as calculated in step 2.a) is the ratio of the survival probability at age $x$ estimated from the HRS to the survival probability obtained from the CDC. Step 2.b) rescales survival probabilities from the HRS according to $a$. Because step 2.b) may result in probabilities above one, step 2.b) $i$ is introduced. Steps 2.c) and 2.d) are needed because survival can be broken down into the probability of being employed, being retired, and being out of the labor force or unemployed. Step 2.c) calculates a scaling factor similar to that of step 2.a), and step 2.d) applies this factor in a manner similar to that of step 2.b). Step 2.e) updates the distribution of states according to adjusted transition probabilities. The algorithm then moves to the next age, and the updated distribution is used in step 2. The updating of the distribution thus ensures that the algorithm keeps track of the composition of the population. The final step 3 implements the assumption that age 99 is the oldest possible age. 


\section{B Additional tables and figures}

This section includes detailed tables and additional figures, supplementing the results presented in section 3 of the paper. Table B1 shows findings for the total population. Tables B2 to B4 add to the results on racial/ethnic differences. Tables B5 to B7 show results by gender and education. Results by race/ethnicity, gender, and education are given in tables B8 to B17. Finally, tables B18 to B20 show how remaining life expectancy at age 50 is distributed among work, retirement, and being out of the labor force. Results not accounting for any of these dimensions (race/ethnicity; gender; education) and relating to the total population are available upon request from the authors. Confidence intervals are given only for a few selected quantities to keep the number of results manageable. As discussed in the main text the sample size of some groups is small, especially for blacks and Hispanics with college degree.

Table B1: Remaining life expectancy at age 50, working life expectancy at age 50, and proportion of remaining life expectancy spent working; total;

\begin{tabular}{lrrrr}
\hline \hline & 1995 & 2000 & 2005 & 2010 \\
\hline Males & & & & \\
Life expectancy at age 50 & 26.7 & 27.9 & 28.5 & 29.5 \\
Working life expectancy at age 50 & 14.3 & 13.1 & 14.2 & 12.7 \\
95\% Confidence interval, lower bound & 13.9 & 12.7 & 13.8 & 12.1 \\
95\% Confidence interval, upper bound & 14.7 & 13.5 & 14.7 & 13.2 \\
\% of life expectancy spent working & $53.5 \%$ & $47.2 \%$ & $49.9 \%$ & $42.9 \%$ \\
$95 \%$ Confidence interval, lower bound & $52.0 \%$ & $45.7 \%$ & $48.4 \%$ & $41.1 \%$ \\
$95 \%$ Confidence interval, upper bound & $55.1 \%$ & $48.5 \%$ & $51.4 \%$ & $44.8 \%$ \\
& & & & \\
Females & 31.3 & 31.7 & 32.2 & 33.1 \\
Life expectancy at age 50 & 11.4 & 10.7 & 11.6 & 11.0 \\
Working life expectancy at age 50 & 11.0 & 10.3 & 11.1 & 10.5 \\
$95 \%$ confidence interval, lower bound & 11.8 & 11.0 & 12.1 & 11.6 \\
$95 \%$ confidence interval, upper bound & $35.1 \%$ & $32.4 \%$ & $34.6 \%$ & $31.8 \%$ \\
\% of life expectancy spent working & $37.8 \%$ & $34.8 \%$ & $37.5 \%$ & $35.1 \%$ \\
$95 \%$ confidence interval, lower bound & $36.5 \%$ & $33.6 \%$ & $36.0 \%$ & $33.4 \%$ \\
$95 \%$ confidence interval, upper bound & $18.4 \%$ & $14.8 \%$ & $15.3 \%$ & $11.2 \%$ \\
\hline Difference relative WLE male/female & & & &
\end{tabular}


Table B2: Remaining life expectancy at age 50, working life expectancy at age 50, and proportion of remaining life expectancy spent working; whites;

\begin{tabular}{crrrr}
\hline \hline & 1995 & 2000 & 2005 & 2010 \\
\hline White males & & & & \\
Life expectancy at age 50 & 27.1 & 28.2 & 28.8 & 29.7 \\
Working life expectancy at age 50 & 15.0 & 13.6 & 14.7 & 13.2 \\
95\% confidence interval, lower bound & 14.5 & 13.1 & 14.2 & 12.5 \\
95\% confidence interval, upper bound & 15.4 & 14.0 & 15.2 & 13.8 \\
\% of life expectancy spent working & $55.3 \%$ & $48.2 \%$ & $51.1 \%$ & $44.4 \%$ \\
95\% confidence interval, lower bound & $53.5 \%$ & $46.6 \%$ & $49.5 \%$ & $42.1 \%$ \\
95\% confidence interval, upper bound & $57.0 \%$ & $49.8 \%$ & $52.9 \%$ & $46.5 \%$ \\
& & & & \\
White females & 31.5 & 31.9 & 32.4 & 33.2 \\
Life expectancy at age 50 & 11.8 & 11.2 & 12.2 & 11.4 \\
Working life expectancy at age 50 & 11.3 & 10.7 & 11.7 & 10.7 \\
$95 \%$ confidence interval, lower bound & 12.3 & 11.7 & 12.7 & 12.1 \\
95\% confidence interval, upper bound & $37.4 \%$ & $35.2 \%$ & $37.7 \%$ & $34.4 \%$ \\
\% of life expectancy spent working & $35.7 \%$ & $33.6 \%$ & $36.1 \%$ & $32.3 \%$ \\
95\% confidence interval, lower bound & $38.9 \%$ & $36.5 \%$ & $39.4 \%$ & $36.4 \%$ \\
95\% confidence interval, upper bound & $17.9 \%$ & $13.1 \%$ & $13.4 \%$ & $10.0 \%$ \\
\hline Difference relative WLE male/female & & & & \\
\hline \hline
\end{tabular}

Table B3: Remaining life expectancy at age 50, working life expectancy at age 50, and proportion of remaining life expectancy spent working; blacks;

\begin{tabular}{crrrr}
\hline \hline & 1995 & 2000 & 2005 & 2010 \\
\hline Black males & & & & \\
Life expectancy at age 50 & 22.7 & 24.2 & 24.9 & 26.6 \\
Working life expectancy at age 50 & 10.5 & 9.0 & 10.8 & 9.1 \\
95\% confidence interval, lower bound & 9.4 & 7.9 & 9.3 & 7.8 \\
95\% confidence interval, upper bound & 11.5 & 10.2 & 12.2 & 10.6 \\
\% of life expectancy spent working & $46.2 \%$ & $37.1 \%$ & $43.3 \%$ & $34.4 \%$ \\
$95 \%$ confidence interval, lower bound & $41.5 \%$ & $32.6 \%$ & $37.4 \%$ & $29.2 \%$ \\
$95 \%$ confidence interval, upper bound & $50.8 \%$ & $42.1 \%$ & $48.9 \%$ & $39.8 \%$ \\
Black females & & & & \\
Life expectancy at age 50 & 28.1 & 28.8 & 29.7 & 31.0 \\
Working life expectancy at age 50 & 10.2 & 9.1 & 9.7 & 8.9 \\
$95 \%$ confidence interval, lower bound & 9.3 & 8.1 & 8.6 & 7.7 \\
95\% confidence interval, upper bound & 11.3 & 10.2 & 10.9 & 10.1 \\
\% of life expectancy spent working & $36.4 \%$ & $31.6 \%$ & $32.8 \%$ & $28.6 \%$ \\
95\% confidence interval, lower bound & $33.3 \%$ & $28.2 \%$ & $29.0 \%$ & $24.8 \%$ \\
$95 \%$ confidence interval, upper bound & $40.1 \%$ & $35.2 \%$ & $36.8 \%$ & $32.6 \%$ \\
Difference relative WLE male/female & $9.8 \%$ & $5.5 \%$ & $10.4 \%$ & $5.8 \%$ \\
\hline \hline
\end{tabular}


Table B4: Remaining life expectancy at age 50, working life expectancy at age 50, and proportion of remaining life expectancy spent working; Hispanics;

\begin{tabular}{crrrr}
\hline \hline & 1995 & 2000 & 2005 & 2010 \\
\hline Hispanic males & & & & \\
Life expectancy at age 50 & 29.2 & 30.3 & 31.1 & 31.4 \\
Working life expectancy at age 50 & 12.1 & 12.6 & 13.0 & 10.3 \\
95\% confidence interval, lower bound & 10.6 & 10.9 & 11.5 & 8.5 \\
95\% confidence interval, upper bound & 13.4 & 14.3 & 14.5 & 12.1 \\
\% of life expectancy spent working & $41.3 \%$ & $41.5 \%$ & $41.8 \%$ & $32.9 \%$ \\
95\% confidence interval, lower bound & $36.3 \%$ & $35.9 \%$ & $37.0 \%$ & $27.2 \%$ \\
95\% confidence interval, upper bound & $45.8 \%$ & $47.2 \%$ & $46.5 \%$ & $38.7 \%$ \\
Hispanic females & & & & \\
Life expectancy at age 50 & 33.2 & 33.8 & 34.7 & 35.2 \\
Working life expectancy at age 50 & 9.2 & 7.9 & 8.0 & 9.4 \\
$95 \%$ confidence interval, lower bound & 8.0 & 6.5 & 6.8 & 7.7 \\
95\% confidence interval, upper bound & 10.6 & 9.1 & 9.2 & 11.1 \\
\% of life expectancy spent working & $27.6 \%$ & $23.2 \%$ & $23.1 \%$ & $26.8 \%$ \\
95\% confidence interval, lower bound & $23.9 \%$ & $19.3 \%$ & $19.5 \%$ & $22.0 \%$ \\
$95 \%$ confidence interval, upper bound & $32.0 \%$ & $27.0 \%$ & $26.6 \%$ & $31.6 \%$ \\
Difference relative WLE male/female & $13.7 \%$ & $18.3 \%$ & $18.7 \%$ & $6.1 \%$ \\
\hline \hline
\end{tabular}

Table B5: Remaining life expectancy at age 50, working life expectancy at age 50, and proportion of remaining life expectancy spent working; less than high school degree

\begin{tabular}{crrrr}
\hline \hline & 1995 & 2000 & 2005 & 2010 \\
\hline Less than high school degree, males & & & & \\
Life expectancy at age 50 & 25.5 & 25.8 & 25.8 & 26.2 \\
Working life expectancy at age 50 & 11.1 & 10.6 & 10.1 & 8.7 \\
95\% confidence interval, lower bound & 10.2 & 9.8 & 9.1 & 7.6 \\
95\% confidence interval, upper bound & 11.9 & 11.5 & 11.2 & 10.0 \\
\% of life expectancy spent working & $43.6 \%$ & $41.3 \%$ & $39.3 \%$ & $33.3 \%$ \\
95\% confidence interval, lower bound & $40.5 \%$ & $38.2 \%$ & $35.6 \%$ & $29.2 \%$ \\
$95 \%$ confidence interval, upper bound & $46.5 \%$ & $44.3 \%$ & $42.9 \%$ & $37.6 \%$ \\
Less than high school degree, females & & & & \\
Life expectancy at age 50 & 30.1 & 29.7 & 29.3 & 31.2 \\
Working life expectancy at age 50 & 8.0 & 6.2 & 6.5 & 7.0 \\
$95 \%$ confidence interval, lower bound & 8.0 & 6.3 & 6.5 & 6.7 \\
$95 \%$ confidence interval, upper bound & 9.7 & 7.7 & 8.2 & 9.1 \\
\% of life expectancy spent working & $26.4 \%$ & $20.8 \%$ & $22.1 \%$ & $22.5 \%$ \\
95\% confidence interval, lower bound & $26.8 \%$ & $21.2 \%$ & $22.4 \%$ & $21.7 \%$ \\
95\% confidence interval, upper bound & $31.9 \%$ & $26.0 \%$ & $28.1 \%$ & $29.1 \%$ \\
Difference relative WLE male/female & $17.2 \%$ & $20.5 \%$ & $17.2 \%$ & $10.9 \%$ \\
\hline \hline
\end{tabular}


Table B6: Remaining life expectancy at age 50, working life expectancy at age 50, and proportion of remaining life expectancy spent working; high school

\begin{tabular}{crrrr}
\hline \hline & 1995 & 2000 & 2005 & 2010 \\
\hline High school, males & & & & \\
Life expectancy at age 50 & 26.3 & 27.4 & 28.0 & 29.3 \\
Working life expectancy at age 50 & 13.3 & 12.2 & 12.8 & 12.0 \\
95\% confidence interval, lower bound & 12.7 & 11.6 & 12.1 & 11.2 \\
95\% confidence interval, upper bound & 13.9 & 12.7 & 13.4 & 12.8 \\
\% of life expectancy spent working & $50.7 \%$ & $44.5 \%$ & $45.7 \%$ & $41.0 \%$ \\
95\% confidence interval, lower bound & $48.4 \%$ & $42.3 \%$ & $43.5 \%$ & $38.2 \%$ \\
95\% confidence interval, upper bound & $52.9 \%$ & $46.4 \%$ & $47.8 \%$ & $43.6 \%$ \\
High school, females & & & & \\
Life expectancy at age 50 & 31.3 & 32.1 & 32.5 & 33.2 \\
Working life expectancy at age 50 & 10.7 & 10.2 & 11.2 & 10.4 \\
$95 \%$ confidence interval, lower bound & 10.8 & 10.4 & 11.3 & 10.4 \\
95\% confidence interval, upper bound & 12.0 & 11.4 & 12.5 & 11.8 \\
\% of life expectancy spent working & $34.2 \%$ & $31.9 \%$ & $34.6 \%$ & $31.3 \%$ \\
95\% confidence interval, lower bound & $34.5 \%$ & $32.4 \%$ & $35.1 \%$ & $31.4 \%$ \\
95\% confidence interval, upper bound & $38.3 \%$ & $35.7 \%$ & $38.7 \%$ & $35.7 \%$ \\
Difference relative WLE male/female & $16.5 \%$ & $12.6 \%$ & $11.2 \%$ & $9.7 \%$ \\
\hline \hline
\end{tabular}

Table B7: Remaining life expectancy at age 50, working life expectancy at age 50, and proportion of remaining life expectancy spent working; high school

\begin{tabular}{crrrr}
\hline \hline & 1995 & 2000 & 2005 & 2010 \\
\hline College, males & & & & \\
Life expectancy at age 50 & 28.2 & 30.1 & 31.1 & 32.0 \\
Working life expectancy at age 50 & 16.8 & 14.8 & 18.5 & 15.3 \\
95\% confidence interval, lower bound & 15.8 & 13.9 & 17.6 & 14.3 \\
95\% confidence interval, upper bound & 17.9 & 15.5 & 19.3 & 16.3 \\
\% of life expectancy spent working & $59.6 \%$ & $49.2 \%$ & $59.3 \%$ & $47.6 \%$ \\
95\% confidence interval, lower bound & $56.2 \%$ & $46.3 \%$ & $56.6 \%$ & $44.4 \%$ \\
95\% confidence interval, upper bound & $63.4 \%$ & $51.7 \%$ & $62.0 \%$ & $50.7 \%$ \\
& & & & \\
College, females & 32.3 & 32.7 & 34.3 & 34.7 \\
Life expectancy at age 50 & 12.1 & 12.3 & 14.0 & 12.5 \\
Working life expectancy at age 50 & 11.8 & 12.1 & 13.8 & 12.2 \\
$95 \%$ confidence interval, lower bound & 13.9 & 13.8 & 15.7 & 14.1 \\
95\% confidence interval, upper bound & $37.4 \%$ & $37.7 \%$ & $41.0 \%$ & $36.0 \%$ \\
\% of life expectancy spent working & $36.6 \%$ & $36.9 \%$ & $40.4 \%$ & $35.3 \%$ \\
95\% confidence interval, lower bound & $43.2 \%$ & $42.6 \%$ & $45.8 \%$ & $40.8 \%$ \\
95\% confidence interval, upper bound & $43.2 \%$ & $11.5 \%$ & $18.3 \%$ & $11.7 \%$ \\
\hline Difference relative WLE male/female & $22.2 \%$ & & & \\
\hline \hline
\end{tabular}


Table B8: Remaining life expectancy at age 50 by race/ethnicity, gender, and education

\begin{tabular}{llcccc}
\hline \hline \multirow{2}{*}{ White males } & & 1995 & 2000 & 2005 & 2010 \\
& less than high school degree & 25.4 & 25.6 & 25.4 & 25.7 \\
& high school degree & 26.5 & 27.6 & 28.3 & 29.3 \\
\multirow{3}{*}{ White females } & college degree & 28.6 & 30.1 & 31.2 & 32.1 \\
& less than high school degree & 30.4 & 29.7 & 28.7 & 30.8 \\
& high school degree & 31.4 & 32.1 & 32.5 & 33.3 \\
& college degree & 32.6 & 33.1 & 34.4 & 34.7 \\
\hline \multirow{2}{*}{ Black males } & less than high school degree & 22.7 & 23.1 & 22.9 & 22.7 \\
& high school degree & 22.8 & 23.7 & 24.9 & 28.8 \\
\multirow{3}{*}{ Black females } & college degree & 22.3 & 28.5 & 29.9 & 30.0 \\
& less than high school degree & 26.4 & 27.5 & 28.5 & 29.6 \\
& high school degree & 29.6 & 30.1 & 30.0 & 31.4 \\
& college degree & 27.7 & 28.3 & 31.5 & 33.1 \\
\hline \multirow{2}{*}{ Hispanic males } & less than high school degree & 28.1 & 29.4 & 31.7 & 31.3 \\
& high school degree & 30.2 & 30.3 & 30.9 & 31.5 \\
& college degree & 31.1 & 34.3 & 29.1 & 31.6 \\
& less than high school degree & 33.4 & 32.5 & 33.5 & 33.3 \\
& high school degree & 32.7 & 37.4 & 37.3 & 37.5 \\
& college degree & 34.0 & 29.5 & 34.1 & 41.0 \\
\hline \hline
\end{tabular}

Table B9: Remaining life expectancy at age 50, working life expectancy at age 50, and proportion of remaining life expectancy spent working; whites, less than high school degree;

\begin{tabular}{crrrr}
\hline \hline & 1995 & 2000 & 2005 & 2010 \\
\hline White males, less than high school degree & & & & \\
Life expectancy at age 50 & 25.4 & 25.6 & 25.4 & 25.7 \\
Working life expectancy at age 50 & 11.7 & 10.8 & 10.2 & 8.1 \\
95\% confidence interval, lower bound & 10.6 & 9.6 & 8.5 & 6.5 \\
95\% confidence interval, upper bound & 12.8 & 12.0 & 11.7 & 10.0 \\
\% of life expectancy spent working & $46.2 \%$ & $42.2 \%$ & $40.1 \%$ & $31.5 \%$ \\
95\% confidence interval, lower bound & $42.3 \%$ & $38.0 \%$ & $34.3 \%$ & $25.1 \%$ \\
95\% confidence interval, upper bound & $50.0 \%$ & $46.2 \%$ & $45.8 \%$ & $38.0 \%$ \\
White females, less than high school degree & & & & \\
Life expectancy at age 50 & 30.4 & 29.7 & 28.7 & 30.8 \\
Working life expectancy at age 50 & 8.5 & 6.3 & 6.8 & 6.4 \\
$95 \%$ confidence interval, lower bound & 7.4 & 5.5 & 5.6 & 4.8 \\
95\% confidence interval, upper bound & 9.7 & 7.3 & 8.0 & 8.1 \\
\% of life expectancy spent working & $28.0 \%$ & $21.4 \%$ & $23.7 \%$ & $20.6 \%$ \\
95\% confidence interval, lower bound & $24.6 \%$ & $18.3 \%$ & $19.5 \%$ & $15.7 \%$ \\
95\% confidence interval, upper bound & $31.5 \%$ & $24.7 \%$ & $27.8 \%$ & $26.1 \%$ \\
Difference relative WLE male/female & $18.2 \%$ & $20.8 \%$ & $16.4 \%$ & $10.8 \%$ \\
\hline \hline
\end{tabular}


Table B10: Remaining life expectancy at age 50, working life expectancy at age 50 , and proportion of remaining life expectancy spent working; whites, high school degree;

\begin{tabular}{crrrr}
\hline \hline & 1995 & 2000 & 2005 & 2010 \\
\hline White males, high school degree & & & & \\
Life expectancy at age 50 & 26.5 & 27.6 & 28.3 & 29.3 \\
Working life expectancy at age 50 & 14.2 & 13.0 & 13.5 & 13.1 \\
95\% confidence interval, lower bound & 13.5 & 12.4 & 12.8 & 12.2 \\
95\% confidence interval, upper bound & 14.9 & 13.5 & 14.2 & 14.0 \\
\% of life expectancy spent working & $53.4 \%$ & $46.9 \%$ & $47.9 \%$ & $44.6 \%$ \\
95\% confidence interval, lower bound & $51.0 \%$ & $44.9 \%$ & $45.5 \%$ & $41.7 \%$ \\
95\% confidence interval, upper bound & $55.7 \%$ & $49.0 \%$ & $50.2 \%$ & $47.5 \%$ \\
White females, high school degree & & & & \\
Life expectancy at age 50 & 31.4 & 32.1 & 32.5 & 33.3 \\
Working life expectancy at age 50 & 11.7 & 11.5 & 12.3 & 11.6 \\
95\% confidence interval, lower bound & 11.0 & 10.9 & 11.7 & 10.8 \\
95\% confidence interval, upper bound & 12.3 & 12.0 & 13.0 & 12.3 \\
\% of life expectancy spent working & $37.2 \%$ & $35.7 \%$ & $37.9 \%$ & $34.8 \%$ \\
95\% confidence interval, lower bound & $35.1 \%$ & $33.9 \%$ & $36.0 \%$ & $32.3 \%$ \\
$95 \%$ confidence interval, upper bound & $39.3 \%$ & $37.5 \%$ & $39.9 \%$ & $37.2 \%$ \\
Difference relative WLE male/female & $16.1 \%$ & $11.2 \%$ & $10.0 \%$ & $9.8 \%$ \\
\hline \hline
\end{tabular}

Table B11: Remaining life expectancy at age 50, working life expectancy at age 50, and proportion of remaining life expectancy spent working; whites, college degree;

\begin{tabular}{crrrr}
\hline \hline & 1995 & 2000 & 2005 & 2010 \\
\hline White males, college degree & & & & \\
Life expectancy at age 50 & 28.6 & 30.1 & 31.2 & 32.1 \\
Working life expectancy at age 50 & 17.6 & 15.7 & 19.1 & 16.1 \\
95\% confidence interval, lower bound & 16.6 & 14.8 & 18.1 & 15.0 \\
95\% confidence interval, upper bound & 18.8 & 16.5 & 20.0 & 17.1 \\
\% of life expectancy spent working & $61.6 \%$ & $52.2 \%$ & $61.3 \%$ & $50.1 \%$ \\
95\% confidence interval, lower bound & $58.0 \%$ & $49.4 \%$ & $58.5 \%$ & $46.8 \%$ \\
$95 \%$ confidence interval, upper bound & $65.4 \%$ & $54.7 \%$ & $64.1 \%$ & $53.3 \%$ \\
White females, college degree & & & & \\
Life expectancy at age 50 & 32.6 & 33.1 & 34.4 & 34.7 \\
Working life expectancy at age 50 & 13.5 & 13.7 & 15.6 & 14.4 \\
$95 \%$ confidence interval, lower bound & 12.4 & 12.8 & 14.6 & 13.3 \\
$95 \%$ confidence interval, upper bound & 14.6 & 14.6 & 16.7 & 15.4 \\
\% of life expectancy spent working & $41.3 \%$ & $41.4 \%$ & $45.3 \%$ & $41.4 \%$ \\
95\% confidence interval, lower bound & $38.1 \%$ & $38.6 \%$ & $42.7 \%$ & $38.4 \%$ \\
95\% confidence interval, upper bound & $45.1 \%$ & $44.4 \%$ & $48.3 \%$ & $44.4 \%$ \\
Difference relative WLE male/female & $20.3 \%$ & $10.7 \%$ & $15.9 \%$ & $8.7 \%$ \\
\hline \hline
\end{tabular}


Table B12: Remaining life expectancy at age 50, working life expectancy at age 50, and proportion of remaining life expectancy spent working; blacks, less than high school degree;

\begin{tabular}{crrrr}
\hline \hline & 1995 & 2000 & 2005 & 2010 \\
\hline Black males, less than high school degree & & & & \\
Life expectancy at age 50 & 22.7 & 23.1 & 22.9 & 22.7 \\
Working life expectancy at age 50 & 8.5 & 8.3 & 7.7 & 7.5 \\
95\% confidence interval, lower bound & 7.1 & 6.7 & 5.8 & 5.4 \\
95\% confidence interval, upper bound & 9.9 & 9.8 & 9.9 & 9.9 \\
\% of life expectancy spent working & $37.4 \%$ & $35.8 \%$ & $33.6 \%$ & $33.2 \%$ \\
95\% confidence interval, lower bound & $31.8 \%$ & $28.9 \%$ & $25.4 \%$ & $23.4 \%$ \\
95\% confidence interval, upper bound & $43.4 \%$ & $42.5 \%$ & $42.6 \%$ & $42.1 \%$ \\
Black females, less than high school degree & & & & \\
Life expectancy at age 50 & 26.4 & 27.5 & 28.5 & 29.6 \\
Working life expectancy at age 50 & 7.1 & 6.2 & 5.9 & 5.9 \\
95\% confidence interval, lower bound & 5.8 & 4.9 & 4.5 & 4.1 \\
95\% confidence interval, upper bound & 8.4 & 7.8 & 7.7 & 8.2 \\
\% of life expectancy spent working & $26.7 \%$ & $22.6 \%$ & $20.8 \%$ & $19.9 \%$ \\
95\% confidence interval, lower bound & $22.2 \%$ & $17.8 \%$ & $15.7 \%$ & $14.0 \%$ \\
95\% confidence interval, upper bound & $31.9 \%$ & $28.2 \%$ & $27.1 \%$ & $27.0 \%$ \\
Difference relative WLE male/female & $10.7 \%$ & $13.3 \%$ & $12.7 \%$ & $13.3 \%$ \\
\hline \hline
\end{tabular}

Table B13: Remaining life expectancy at age 50, working life expectancy at age 50 , and proportion of remaining life expectancy spent working; blacks, high school degree;

\begin{tabular}{crrrr}
\hline \hline & 1995 & 2000 & 2005 & 2010 \\
\hline Black males, high school degree & & & & \\
Life expectancy at age 50 & 22.8 & 23.7 & 24.9 & 28.8 \\
Working life expectancy at age 50 & 11.1 & 9.3 & 11.5 & 8.5 \\
95\% confidence interval, lower bound & 9.4 & 7.6 & 9.3 & 6.8 \\
95\% confidence interval, upper bound & 12.7 & 11.1 & 13.6 & 10.4 \\
\% of life expectancy spent working & $48.6 \%$ & $39.3 \%$ & $46.3 \%$ & $29.6 \%$ \\
95\% confidence interval, lower bound & $42.2 \%$ & $32.2 \%$ & $38.2 \%$ & $23.9 \%$ \\
95\% confidence interval, upper bound & $55.7 \%$ & $46.8 \%$ & $54.3 \%$ & $36.5 \%$ \\
Black females, high school degree & & & & \\
Life expectancy at age 50 & 29.6 & 30.1 & 30.0 & 31.4 \\
Working life expectancy at age 50 & 11.3 & 10.2 & 11.0 & 10.0 \\
$95 \%$ confidence interval, lower bound & 9.9 & 8.7 & 9.7 & 8.6 \\
95\% confidence interval, upper bound & 12.9 & 11.7 & 12.5 & 11.6 \\
\% of life expectancy spent working & $38.2 \%$ & $33.7 \%$ & $36.8 \%$ & $31.9 \%$ \\
95\% confidence interval, lower bound & $33.3 \%$ & $28.8 \%$ & $32.0 \%$ & $27.7 \%$ \\
95\% confidence interval, upper bound & $43.7 \%$ & $38.9 \%$ & $41.9 \%$ & $36.7 \%$ \\
Difference relative WLE male/female & $10.4 \%$ & $5.5 \%$ & $9.5 \%$ & $-2.3 \%$ \\
\hline \hline
\end{tabular}


Table B14: Remaining life expectancy at age 50, working life expectancy at age 50, and proportion of remaining life expectancy spent working; blacks, college degree;

\begin{tabular}{crrrr}
\hline \hline & 1995 & 2000 & 2005 & 2010 \\
\hline Black males, college degree & & & & \\
Life expectancy at age 50 & 22.3 & 28.5 & 29.9 & 30.0 \\
Working life expectancy at age 50 & 14.8 & 9.1 & 19.2 & 17.3 \\
95\% confidence interval, lower bound & 10.3 & 6.3 & 15.4 & 13.0 \\
95\% confidence interval, upper bound & 20.8 & 12.7 & 22.6 & 21.4 \\
\% of life expectancy spent working & $66.5 \%$ & $31.7 \%$ & $64.2 \%$ & $57.8 \%$ \\
95\% confidence interval, lower bound & $48.8 \%$ & $22.3 \%$ & $53.5 \%$ & $45.0 \%$ \\
95\% confidence interval, upper bound & $84.4 \%$ & $46.4 \%$ & $74.1 \%$ & $70.2 \%$ \\
Black females, college degree & & & & \\
Life expectancy at age 50 & 27.7 & 28.3 & 31.5 & 33.1 \\
Working life expectancy at age 50 & 13.4 & 11.3 & 13.9 & 10.6 \\
95\% confidence interval, lower bound & 10.4 & 8.8 & 11.0 & 8.7 \\
95\% confidence interval, upper bound & 16.5 & 14.1 & 17.0 & 12.6 \\
\% of life expectancy spent working & $48.1 \%$ & $40.1 \%$ & $44.1 \%$ & $31.9 \%$ \\
95\% confidence interval, lower bound & $37.9 \%$ & $31.4 \%$ & $35.4 \%$ & $26.5 \%$ \\
95\% confidence interval, upper bound & $58.7 \%$ & $50.9 \%$ & $54.5 \%$ & $38.9 \%$ \\
Difference relative WLE male/female & $18.4 \%$ & $-8.4 \%$ & $20.1 \%$ & $26.0 \%$ \\
\hline \hline
\end{tabular}

Table B15: Remaining life expectancy at age 50, working life expectancy at age 50, and proportion of remaining life expectancy spent working; Hispanics, less than high school degree;

\begin{tabular}{crrrr}
\hline \hline & 1995 & 2000 & 2005 & 2010 \\
\hline Hispanic males, less than high school degree & & & & \\
Life expectancy at age 50 & 28.1 & 29.4 & 31.7 & 31.3 \\
Working life expectancy at age 50 & 10.4 & 10.9 & 10.6 & 9.0 \\
95\% confidence interval, lower bound & 8.6 & 9.1 & 8.6 & 6.7 \\
95\% confidence interval, upper bound & 12.2 & 12.7 & 12.7 & 11.5 \\
\% of life expectancy spent working & $36.9 \%$ & $37.1 \%$ & $33.6 \%$ & $28.7 \%$ \\
95\% confidence interval, lower bound & $30.2 \%$ & $31.2 \%$ & $27.5 \%$ & $21.3 \%$ \\
95\% confidence interval, upper bound & $43.3 \%$ & $44.1 \%$ & $40.8 \%$ & $37.3 \%$ \\
Hispanic females, less than high school degree & & & & \\
Life expectancy at age 50 & 33.4 & 32.5 & 33.5 & 33.3 \\
Working life expectancy at age 50 & 7.3 & 5.9 & 5.6 & 7.5 \\
95\% confidence interval, lower bound & 5.9 & 4.5 & 4.3 & 5.4 \\
95\% confidence interval, upper bound & 9.1 & 7.3 & 7.1 & 9.8 \\
\% of life expectancy spent working & $21.9 \%$ & $18.1 \%$ & $16.8 \%$ & $22.4 \%$ \\
95\% confidence interval, lower bound & $17.7 \%$ & $13.9 \%$ & $12.8 \%$ & $16.3 \%$ \\
95\% confidence interval, upper bound & $27.6 \%$ & $22.8 \%$ & $21.1 \%$ & $29.2 \%$ \\
Difference relative WLE male/female & $15.0 \%$ & $19.0 \%$ & $16.8 \%$ & $6.3 \%$ \\
\hline \hline
\end{tabular}


Table B16: Remaining life expectancy at age 50, working life expectancy at age 50, and proportion of remaining life expectancy spent working; Hispanics, high school degree;

\begin{tabular}{crrrr}
\hline \hline & 1995 & 2000 & 2005 & 2010 \\
\hline Hispanic males, high school degree & & & & \\
Life expectancy at age 50 & 30.2 & 30.3 & 30.9 & 31.5 \\
Working life expectancy at age 50 & 12.7 & 12.8 & 13.6 & 10.7 \\
95\% confidence interval, lower bound & 10.2 & 9.4 & 11.4 & 8.1 \\
95\% confidence interval, upper bound & 15.2 & 16.2 & 16.3 & 13.9 \\
\% of life expectancy spent working & $41.9 \%$ & $42.1 \%$ & $44.0 \%$ & $33.9 \%$ \\
95\% confidence interval, lower bound & $33.7 \%$ & $30.3 \%$ & $36.5 \%$ & $25.0 \%$ \\
95\% confidence interval, upper bound & $51.5 \%$ & $53.8 \%$ & $52.3 \%$ & $43.5 \%$ \\
Hispanic females, high school degree & & & & \\
Life expectancy at age 50 & 32.7 & 37.4 & 37.3 & 37.5 \\
Working life expectancy at age 50 & 11.5 & 9.7 & 11.8 & 11.5 \\
$95 \%$ confidence interval, lower bound & 9.4 & 7.6 & 9.3 & 9.2 \\
95\% confidence interval, upper bound & 14.2 & 12.1 & 14.5 & 13.9 \\
\% of life expectancy spent working & $35.1 \%$ & $26.1 \%$ & $31.8 \%$ & $30.6 \%$ \\
95\% confidence interval, lower bound & $28.0 \%$ & $20.5 \%$ & $25.1 \%$ & $24.5 \%$ \\
$95 \%$ confidence interval, upper bound & $44.2 \%$ & $32.6 \%$ & $39.5 \%$ & $37.8 \%$ \\
Difference relative WLE male/female & $6.8 \%$ & $16.1 \%$ & $12.2 \%$ & $3.3 \%$ \\
\hline \hline
\end{tabular}

Table B17: Remaining life expectancy at age 50, working life expectancy at age 50, and proportion of remaining life expectancy spent working; Hispanics, college degree;

\begin{tabular}{crrrr}
\hline \hline & 1995 & 2000 & 2005 & 2010 \\
\hline Hispanic males, college degree & & & & \\
Life expectancy at age 50 & 31.1 & 34.3 & 29.1 & 31.6 \\
Working life expectancy at age 50 & 15.7 & 17.5 & 19.2 & 13.8 \\
95\% confidence interval, lower bound & 11.7 & 13.5 & 15.4 & 11.5 \\
95\% confidence interval, upper bound & 20.5 & 21.6 & 22.9 & 17.5 \\
\% of life expectancy spent working & $50.4 \%$ & $51.1 \%$ & $65.9 \%$ & $43.7 \%$ \\
95\% confidence interval, lower bound & $36.3 \%$ & $38.6 \%$ & $51.2 \%$ & $34.1 \%$ \\
95\% confidence interval, upper bound & $66.7 \%$ & $65.3 \%$ & $78.7 \%$ & $58.8 \%$ \\
Hispanic females, college degree & & & & \\
Life expectancy at age 50 & 34.0 & 29.5 & 34.1 & 41.0 \\
Working life expectancy at age 50 & 10.3 & 14.1 & 10.7 & 12.9 \\
95\% confidence interval, lower bound & 8.0 & 9.8 & 7.7 & 9.3 \\
$95 \%$ confidence interval, upper bound & 13.8 & 19.2 & 14.7 & 17.9 \\
\% of life expectancy spent working & $30.5 \%$ & $47.9 \%$ & $31.5 \%$ & $31.5 \%$ \\
95\% confidence interval, lower bound & $22.4 \%$ & $29.1 \%$ & $21.3 \%$ & $22.6 \%$ \\
95\% confidence interval, upper bound & $44.2 \%$ & $63.9 \%$ & $45.1 \%$ & $44.4 \%$ \\
Difference relative WLE male/female & $19.9 \%$ & $3.1 \%$ & $34.4 \%$ & $12.2 \%$ \\
\hline \hline
\end{tabular}


Table B18: Decomposition of life expectancy into working life expectancy, life expectancy in retirement, and life expectancy out of the labor force; whites by gender and education

\begin{tabular}{lrrrr}
\hline \hline & 1995 & 2000 & 2005 & 2010 \\
\hline Less than high school degree, white males & & & & \\
Working life expectancy & 11.7 & 10.8 & 10.2 & 8.1 \\
Life expectancy in retirement & 10.7 & 11.4 & 11.3 & 12.4 \\
Life expectancy out of the labor force & 2.9 & 3.4 & 3.9 & 5.2 \\
Less than high school degree, white females & & & & \\
Working life expectancy & 8.5 & 6.3 & 6.8 & 6.4 \\
Life expectancy in retirement & 15.4 & 16.0 & 14.5 & 16.7 \\
Life expectancy out of the labor force & 6.5 & 7.4 & 7.4 & 7.7 \\
\hline High school, white males & & & & \\
Working life expectancy & 14.2 & 13.0 & 13.5 & 13.1 \\
Life expectancy in retirement & 11.0 & 12.8 & 12.8 & 13.8 \\
Life expectancy out of the labor force & 1.4 & 1.8 & 1.9 & 2.4 \\
High school, white females & & & & \\
Working life expectancy & 11.7 & 11.5 & 12.3 & 11.6 \\
Life expectancy in retirement & 16.0 & 17.1 & 16.6 & 17.8 \\
Life expectancy out of the labor force & 3.7 & 3.5 & 3.6 & 3.9 \\
\hline College, white males & & & & \\
Working life expectancy & 17.6 & 15.7 & 19.1 & 16.1 \\
Life expectancy in retirement & 10.5 & 13.5 & 11.3 & 14.6 \\
Life expectancy out of the labor force & 0.5 & 1.0 & 0.7 & 1.4 \\
College, white females & & & & \\
Working life expectancy & 13.5 & 13.7 & 15.6 & 14.4 \\
Life expectancy in retirement & 17.1 & 17.5 & 16.9 & 18.2 \\
Life expectancy out of the labor force & 2.1 & 1.9 & 2.0 & 2.1 \\
\hline \hline
\end{tabular}


Table B19: Decomposition of life expectancy into working life expectancy, life expectancy in retirement, and life expectancy out of the labor force; blacks by gender and education

\begin{tabular}{lrrrr}
\hline \hline & 1995 & 2000 & 2005 & 2010 \\
\hline Less than high school degree, black males & & & & \\
Working life expectancy & 8.5 & 8.3 & 7.7 & 7.5 \\
Life expectancy in retirement & 10.2 & 10.0 & 9.6 & 9.5 \\
Life expectancy out of the labor force & 4.0 & 4.8 & 5.6 & 5.6 \\
Less than high school degree, black females & & & & \\
Working life expectancy & 7.1 & 6.2 & 5.9 & 5.9 \\
Life expectancy in retirement & 12.9 & 13.6 & 13.7 & 14.9 \\
Life expectancy out of the labor force & 6.4 & 7.6 & 8.8 & 8.8 \\
\hline High school, black males & & & & \\
Working life expectancy & 11.1 & 9.3 & 11.5 & 8.5 \\
Life expectancy in retirement & 9.3 & 10.4 & 10.1 & 15.7 \\
Life expectancy out of the labor force & 2.5 & 4.0 & 3.3 & 4.6 \\
High school, black females & & & & \\
Working life expectancy & 11.3 & 10.2 & 11.0 & 10.0 \\
Life expectancy in retirement & 14.7 & 15.9 & 14.7 & 16.2 \\
Life expectancy out of the labor force & 3.6 & 4.1 & 4.2 & 5.2 \\
\hline College, black males & & & & \\
Working life expectancy & 14.8 & 9.1 & 19.2 & 17.3 \\
Life expectancy in retirement & 6.9 & 17.1 & 10.2 & 11.0 \\
Life expectancy out of the labor force & 0.6 & 2.4 & 0.5 & 1.6 \\
College, black females & 13.4 & 11.3 & 13.9 & 10.6 \\
Working life expectancy & 12.9 & 14.6 & 15.0 & 20.6 \\
Life expectancy in retirement & 1.5 & 2.4 & 2.6 & 1.9 \\
Life expectancy out of the labor force & & & &
\end{tabular}


Table B20: Decomposition of life expectancy into working life expectancy, life expectancy in retirement, and life expectancy out of the labor force; Hispanics by gender and education

\begin{tabular}{lrrrr}
\hline \hline & 1995 & 2000 & 2005 & 2010 \\
\hline Less than high school degree, Hispanic males & & & & \\
Working life expectancy & 10.4 & 10.9 & 10.6 & 9.0 \\
Life expectancy in retirement & 13.6 & 13.9 & 16.0 & 16.3 \\
Life expectancy out of the labor force & 4.2 & 4.5 & 5.1 & 6.0 \\
Less than high school degree, Hispanic females & & & & \\
Working life expectancy & 7.3 & 5.9 & 5.6 & 7.5 \\
Life expectancy in retirement & 18.5 & 18.2 & 19.5 & 18.4 \\
Life expectancy out of the labor force & 7.6 & 8.4 & 8.3 & 7.4 \\
\hline High school, Hispanic males & & & & \\
Working life expectancy & 12.7 & 12.8 & 13.6 & 10.7 \\
Life expectancy in retirement & 15.3 & 14.8 & 15.3 & 15.8 \\
Life expectancy out of the labor force & 2.3 & 2.7 & 2.0 & 5.0 \\
High school, Hispanic females & & & & \\
Working life expectancy & 11.5 & 9.7 & 11.8 & 11.5 \\
Life expectancy in retirement & 17.5 & 22.8 & 22.0 & 22.7 \\
Life expectancy out of the labor force & 3.6 & 4.8 & 3.5 & 3.3 \\
\hline College, Hispanic males & & & & \\
Working life expectancy & 15.7 & 17.5 & 19.2 & 13.8 \\
Life expectancy in retirement & 14.8 & 15.4 & 8.9 & 16.1 \\
Life expectancy out of the labor force & 0.6 & 1.4 & 1.0 & 1.6 \\
College, Hispanic females & & & & \\
Working life expectancy & 10.3 & 14.1 & 10.7 & 12.9 \\
Life expectancy in retirement & 22.0 & 13.2 & 19.4 & 25.7 \\
Life expectancy out of the labor force & 1.6 & 2.1 & 4.0 & 2.4 \\
\hline \hline
\end{tabular}

